\title{
Pharmacological blockage of the AHR-CYP1A1 axis: a call for in vivo evidence
}

\author{
N. R. Coelho ${ }^{1}$ A. B. Pimpão ${ }^{1}$ - M. J. Correia ${ }^{1}$ T. C. Rodrigues ${ }^{1}$ - E. C. Monteiro ${ }^{1}$ J. Morello ${ }^{1}$ - S. A. Pereira ${ }^{1}$ (D)
}

Received: 9 June 2021 / Revised: 27 October 2021 / Accepted: 3 November 2021 / Published online: 20 November 2021

(c) The Author(s), under exclusive licence to Springer-Verlag GmbH Germany, part of Springer Nature 2021

\begin{abstract}
The aryl hydrocarbon receptor (AHR) is a ligand-activated transcription factor that can be activated by structurally diverse compounds arising from the environment and the microbiota and host metabolism. Expanding evidence has been shown that the modulation of the canonical pathway of AHR occurs during several chronic diseases and that its abrogation might be of clinical interest for metabolic and inflammatory pathological processes. However, most of the evidence on the pharmacological abrogation of the AHR-CYP1A1 axis has been reported in vitro, and therefore, guidance for in vivo studies is needed. In this review, we cover the state-of-the-art of the pharmacodynamic and pharmacokinetic properties of AHR antagonists and CYP1A1 inhibitors in different in vivo rodent (mouse or rat) models of disease. This review will serve as a road map for those researchers embracing this emerging therapeutic area targeting the AHR. Moreover, it is a timely opportunity as the first AHR antagonists have recently entered the clinical stage of drug development.
\end{abstract}

Keywords Aryl hydrocarbon receptor $\cdot$ CYP1A1 $\cdot$ Metabolism $\cdot$ In vivo $\cdot$ Inflammation $\cdot$ Oxidative stress

\section{Introductory note to the aryl hydrocarbon receptor (AHR)}

The aryl hydrocarbon receptor (AHR) is a ligand-activated transcription factor that belongs to the basic helix-loophelix/Per-Arnt-Sim (bHLH/PAS) family with important functions in sensing and incorporating environmental and outer stimuli (light-dark, $\mathrm{O}_{2}$ alterations, xenobiotic exposure, and microbiota metabolites) into cellular adaptive responses (reviewed by [1]). Other members of this family are the CLOCK-BMAL1 (key components of the circadian clock), the hypoxia-inducible factors (HIFs), and the aryl hydrocarbon receptor translocator (ARNT, also named HIF-1 $\beta$ ), and interesting evidence on the cross-play among

NR Coelho and AB Pimpão have the same contribution. J Morello and SA Pereira have the same contribution.

S. A. Pereira

sofia.pereira@nms.unl.pt

1 CEDOC, NOVA Medical School, Universidade Nova de Lisboa, 1169-056 Lisboa, Portugal them have been reported (reviewed by [2]). In the present review, a brief introduction will be given to the AHRCYP1A1 axis, but we would like to invite the reader to find more information about these druggable targets in the excellent reviews suggested throughout this introductory note.

As a cytosolic protein, the AHR exists in an inactive state bound to the chaperones heat shock protein 90 (HSP90), HSP90-associated co-chaperone p23, AHR-interacting protein (AIP), also called hepatitis $\mathrm{B}$ virus $\mathrm{X}$-associated protein 2 (XAP2), and tyrosine kinase c-Src. This chaperone complex maintains the proper folding and assures the ligand-binding competency and, overall, the transcriptional effectiveness of AHR (reviewed by [3, 4]).

AHR ligands come from the environment and from the microbiota and cellular metabolism. There is a wide variety of compounds with different chemical properties, structure, and binding affinities, which have been recognized as AHR ligands.

Among the exogenous compounds, it may be referred environmental contaminants including the halogenated aromatic hydrocarbons (HAH), such as 2,3,7,8-tetrachlorodibenzo-pdioxin (TCDD), 2,3,7,8-tetrachlorodibenzofuran (TCDF), and 3,4,3',4,'5-pentachlorobiphenyl (PCB), and the polycyclic aromatic hydrocarbons $(\mathrm{PAH})$, such as benzo[a]pyrene $(\mathrm{B}[\mathrm{a}] \mathrm{P})$ and 3-methylcholanthrene (3-MC). In addition, some dietary substances have been also described including polyphenols 
(quercetin, resveratrol, curcumin, indole-3-carbinol) (reviewed by $[5,6])$.

Among the endogenous ligands, some ultraviolet photoproducts of tryptophan have been described as the 6-formylindolo[3,2-b]carbazole (FICZ); the indigoids indigo and indirubin; the kynurenine (Kyn) and its metabolites including kynurenic acid; the metabolites of arachidonic acid like lipoxin 4A, prostaglandin G2, and hydroxyeicosatetraenoic acid; and cystine [7] and the tetrapyrroles derived from heme, biliverdin, and bilirubin (reviewed by [8, 9]). This vast ligand promiscuity converges in the fact that according to the ligand, AHR might be activated in a diverse manner and in a cell- and tissue-dependent way [3, 5].

AHR has long been associated with an adaptive response to environmental contaminants, most of which are manmade and not related to human physiology. This response activates the AHR canonical or adaptive pathway, which involves AHR-ARNT heterodimer binding DNA at xenobiotic response elements (XRE), including xenobiotic enzymes and transporters that allow environmental contaminants detoxification (reviewed by [4, 10, 11]). The CYP1A1 expression is a sensitive marker of the activation of this route [12]. Moreover, a negative regulatory feedback mechanism is present, with the induction of AHR repressor (AHRR) gene, capable of competing with AHR for ARNT, originating a transcriptionally inactive heterodimer and thus repressing AHR transcriptional activity [13]. Alternatively, several exogenous ligands (e.g., polyphenols as resveratrol or quercetin) activate the AHR alternative pathway, triggering the expression of the antioxidant and anti-inflammatory paraoxonase 1 (PON-1) [11]. Besides ARNT, the AHR also has non-canonical dimerization partners that will activate the transcription of non-consensus xenobiotic response elements (NC-XRE). One of these novel proteins is the tumor suppressor Kruppel-like factor 6 (KLF6) that is involved in the regulation of cellular differentiation, proliferation, and apoptosis [14]. Also, the AHR can interplay with other proteins, most notably with NF-kB subunits and ER $\alpha$. At final steps, the AHR undergoes proteasomal degradation (Fig. 1).

To add more complexity, several lines of research have documented ligand-independent AHR activation, namely modulation by cAMP [15], oxidized LDL [16], vascular shear stress [17], or even reactive oxygen species (ROS) [18].

The mechanism by which AHR ligands affect physiological processes appears to involve multiple interactions between AHR and other signaling pathways (reviewed extensively by $[3,4,10,11])$ or may be a consequence of a change in the activity of metabolic enzymes and transporters, which are AHR target genes that modify the availability and disposition of endogenous metabolites (e.g., estrogen, arachidonic acid, melatonin) [19-21]. AHR target genes include several drug-metabolizing enzymes belonging to the cytochrome P450, like cytochrome P450, family
1, subfamily A, polypeptide 1 (CYP1A1), CYP1A2 and CYP1B1, aldehyde dehydrogenase 3 (ALDH3), and UDP glucuronosyltransferase family 1 member A1 (UGT1A1) [22-24] and transporters such as the ATP binding cassette subfamily B member 1 (ABCB1) [25].

\section{Pharmacological targeting of AHR-CYP1A1 axis in vivo}

In this review, we aim to compile the state-of-the-art concerning AHR antagonists and CYP1A1 inhibitors, seeking consensus for their use in pharmacological in vivo studies. The role of the AHR axis in pathophysiology is expanding fast; however, many of these compounds are non-selective, and their pharmacology is poorly characterized. We summarized the pharmacodynamic and pharmacokinetic characteristics of AHR antagonists and CYP1A1 inhibitors that were tested in mouse (Mus musculus) and rat (Rattus norvegicus), which represent fundamental animal models of disease in translational research studies. While the blockade of AHR has been consistently described in cardiovascular diseases [30, 31], it must be mentioned that in other fields, including cancer, the AHR signaling is dichotomous (i.e., whereas in some type of cancer, the activity of AHR contributes to growth and progression, in other types of tumors, it may suppress them) [32].

For the accomplishment of this review, a search in $P u b$ Med was performed using the following keywords: aryl hydrocarbon receptor antagonist; AHR antagonist; CYP1A1 inhibitor; mice; rat; rodents; and in vivo until the end of June of 2021 . Herein, for the sake of a better characterization for in vivo usage, we included all studies that reported any pharmacological effect of these drugs, even without a detailed description on the role of AHR-CYP1A1 in the underlying mechanism of disease. For all eligible studies, we provided a summing up of the conclusion in the main text of the manuscript and reserved the details on experimental approach and outcomes for Tables 1 and 2.

\section{AHR antagonists}

AHR might activate different signaling pathways (Fig. 1). Herein, we will focus on the main one, the canonical AHR-CYP1A1 axis, and particularly on the putative pharmacological properties of compounds that abrogate its ligand-dependent activation. These compounds have been evaluated in several models of disease. We annotated the animal species (strain, sex, and age) and the chemical or biological agents used as model of disease, together with the pharmacological properties of these compounds: drug administration route, frequency and duration of the treatment, pharmacokinetic properties, effects on the AHR axis 


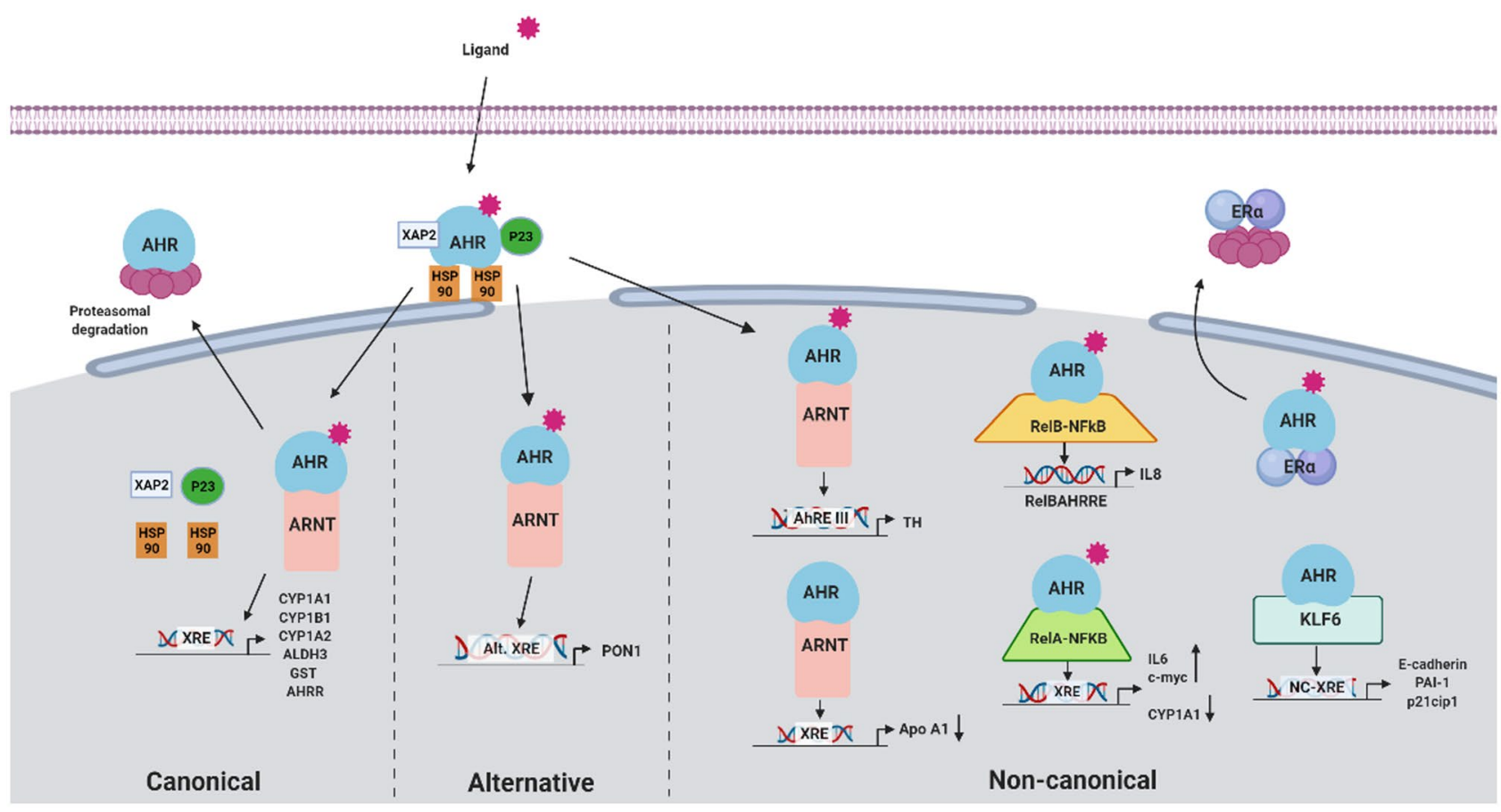

Fig. 1 Representations of ligand-dependent AHR activation pathways. Inactive AHR is localized at the cytoplasm complexed to some chaperones and other elements (HSP90, XAP2, p23, c-Src). Upon ligand binding, conformational changes allow AHR to translocate to the nucleus, where it dissociates from its chaperone complex. Depending on the ligand, AHR can follow either ARNT-dependent or ARNT-independent pathways. In the ARNT-dependent pathways, the AHR-ligand complex dimerizes with its binding partner ARNT. The ligand-AHR-ARNT complex will activate or repress the expression of different genes depending on the type of ligand. Canonical pathway (left side). AHR binding to Kyn, HAH (e.g., dioxin), or PAH (e.g., B[a]P) activates the canonical pathway; the dimer AHR-ARNT binds to xenobiotic response elements (XRE) and drives the expression of xenobiotic metabolizing enzymes such as CYP1A1, the prototypical target gene of AHR. The AHR-ARNT complex promotes gene expression by recruiting several components of the transcriptional machinery and fulfilled this function; AHR activity ends by the dissociation of the complex from the DRE to be exported from the nucleus, where it enrolls in ubiquitin-mediated proteasomal degradation [26]. Moreover, a negative regulatory feedback mechanism is present, with the induction of AHR repressor (AHRR) gene, capable of competing with AHR for ARNT, originating a transcriptionally inactive heterodimer, thus repressing AHR transcriptional activity [13]. Alternative pathway (center). AHR binding to polyphenols such as resveratrol or quercetin activates the alternative pathway by

related genes (AHR, CYP1A1, ARNT, AHRR), and drug response observed in the animal model investigated. The details on the eligible studies of the AHR antagonists are presented at Table 1 . In vitro competitive binding assays, using labeled TCDD or labeled PAL (2-azido-3-[(125) I]iodo-7,8-dibromodibenzo-p-dioxin) as AHR agonists, proved that most molecules target directly the AhR and the $\mathrm{IC}_{50}$ values are presented in Table 1. Despite the same pharmacological target, AHR antagonists are compounds with binding to alternative xenobiotic response elements such as the antioxidant and anti-inflammatory paraoxonase 1 (PON-1). Other noncanonical pathways (right side) include alternative REs of alternative AHR-ARNT related transcriptional responses also observed in tyrosine hydroxylase [27], a precursor enzyme in the synthesis of dopamine and catecholamines, Bax, an apoptosis regulator gene [28], and in TGF- $\beta$ [29]. Also, the AHR can bind to other non-ARNT binding partners, like the Kruppel-like factor 6 (KLF6) or the NF-kB subunits RelA or RelB. ALHD3, aldehyde dehydrogenase 3; AHR, aryl hydrocarbon receptor; AHRE, aryl hydrocarbon response element; AHRR, AHR repressor; ARNT, aryl hydrocarbon receptor nuclear translocator; B[a]P, Benzo[a]pyrene; CYP1A1, cytochrome P450, family 1, subfamily A, polypeptide 1; CYP1A2, cytochrome P450, family 1, subfamily A, polypeptide 2; CYP1B1, cytochrome P450, family 1 , subfamily B, polypeptide 1 ; GST, glutathione $S$-transferase; $\mathrm{HAH}$, halogenated aromatic hydrocarbon; HSP90, heat shock protein 90; KLF6, Kruppel-like factor 6; Kyn, kynurenine; NC-XRE, nonconsensus xenobiotic responsive element; $\mathrm{p} 21 \mathrm{cip} 1$, cyclin-dependent kinase inhibitor 1; p23, HSP90-associated co-chaperone; PAI-1, plasminogen activator inhibitor 1 ; $\mathrm{PAH}$, polycyclic aromatic hydrocarbon; PON1, paraoxonase 1; RelA, nuclear factor NF-kappa-B P65 subunit; RelB, RELB proto-oncogene, NF-kB subunit; TH, tyrosine hydroxylase; XAP2, hepatitis B virus X-associated protein 2 or aryl hydrocarbon receptor-interacting protein (AIP); XRE, xenobiotic responsive element

diverse chemical structures (Fig. 2A), which in addition to different pharmacokinetic profiles (e.g., organ disposition) may account for pharmacodynamic differences. The mostly used and best described AHR antagonist is the CH-223191, which is considered a pure AHR antagonist [33]. Other AHR antagonists might present organ-dependent responses [34] or reduce AHR activation through a partial agonist effect [34-36]. Other compounds, which is the case of resveratrol, have the capability to abrogate the canonical pathway and 


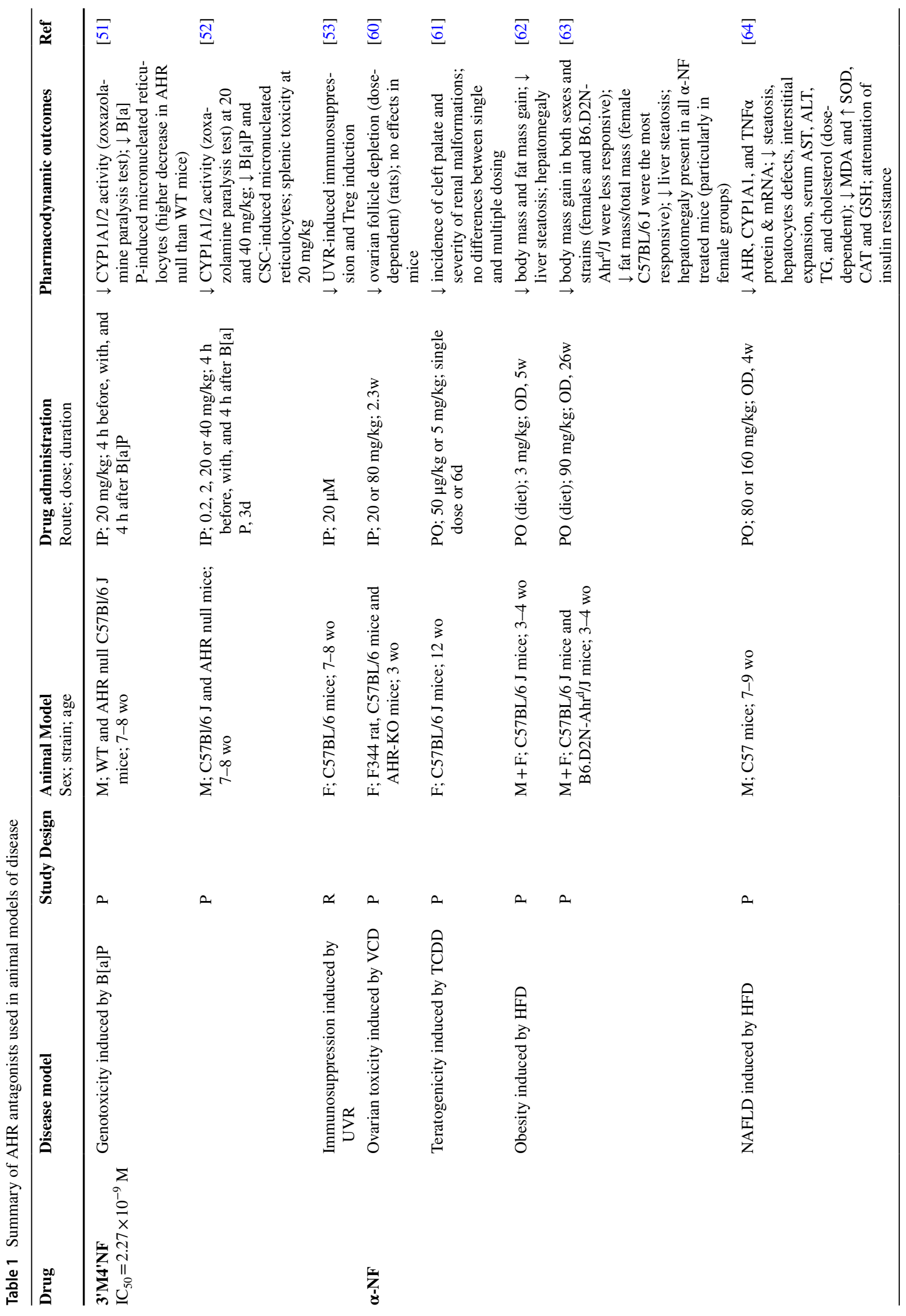




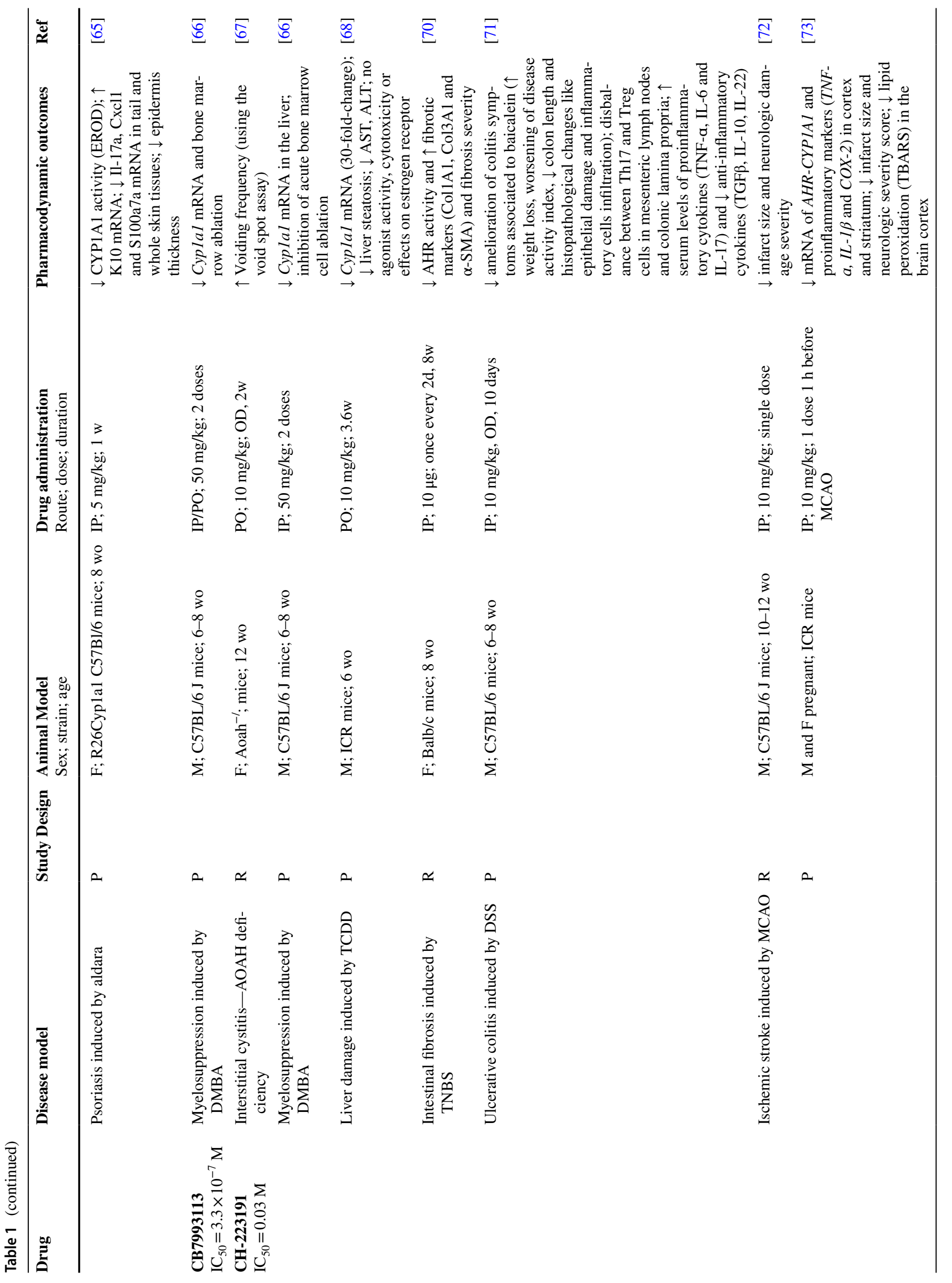




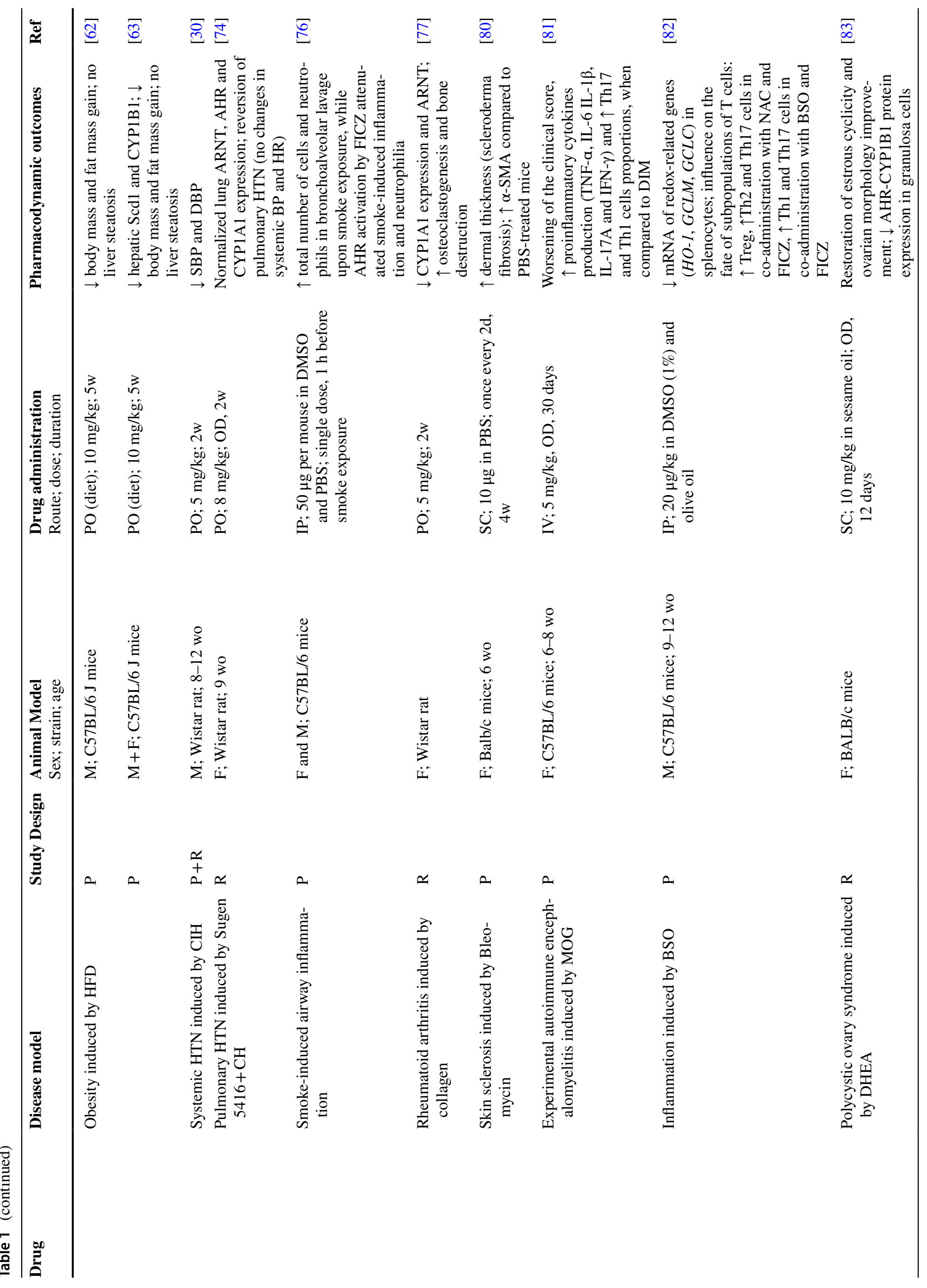




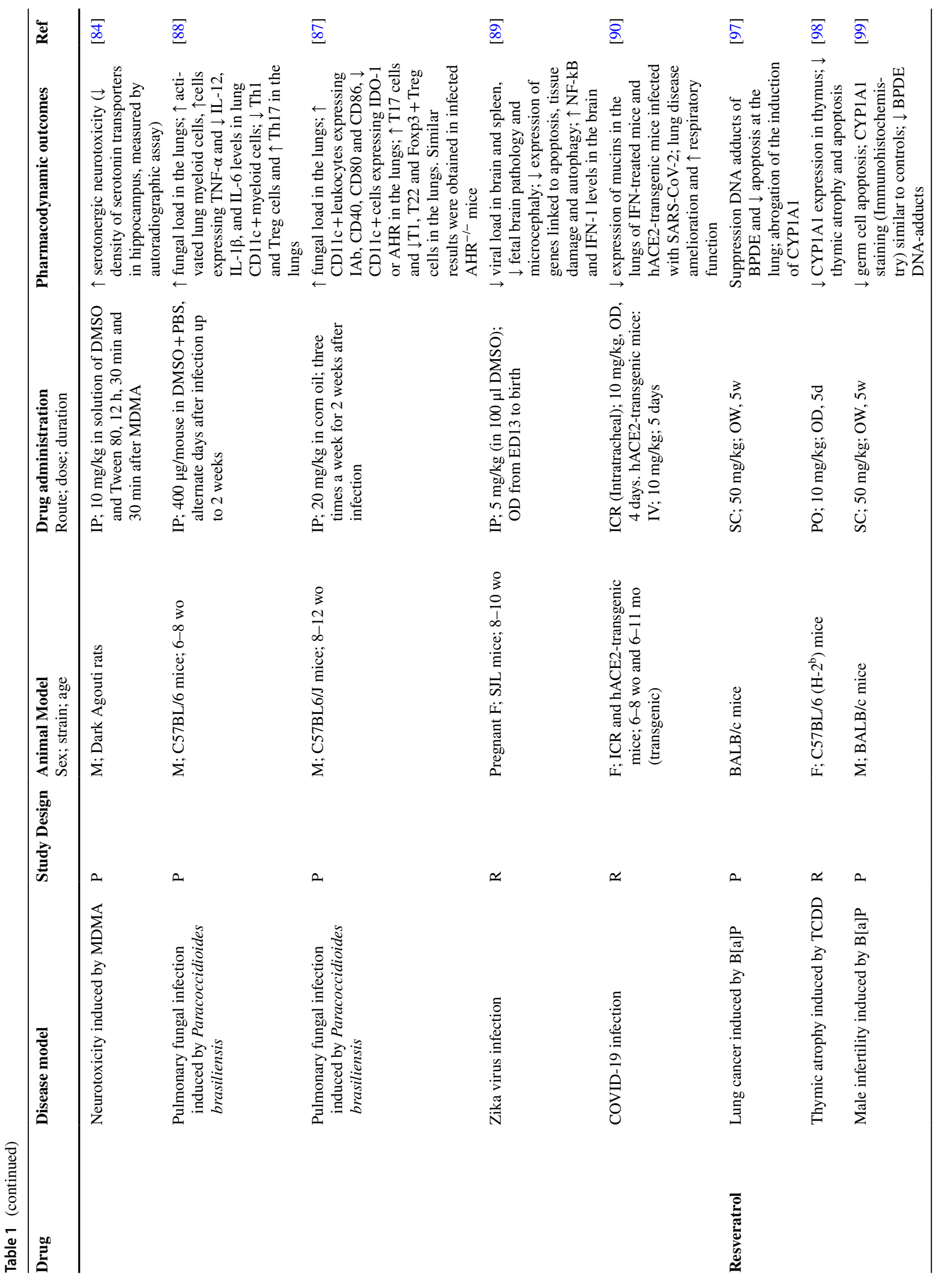




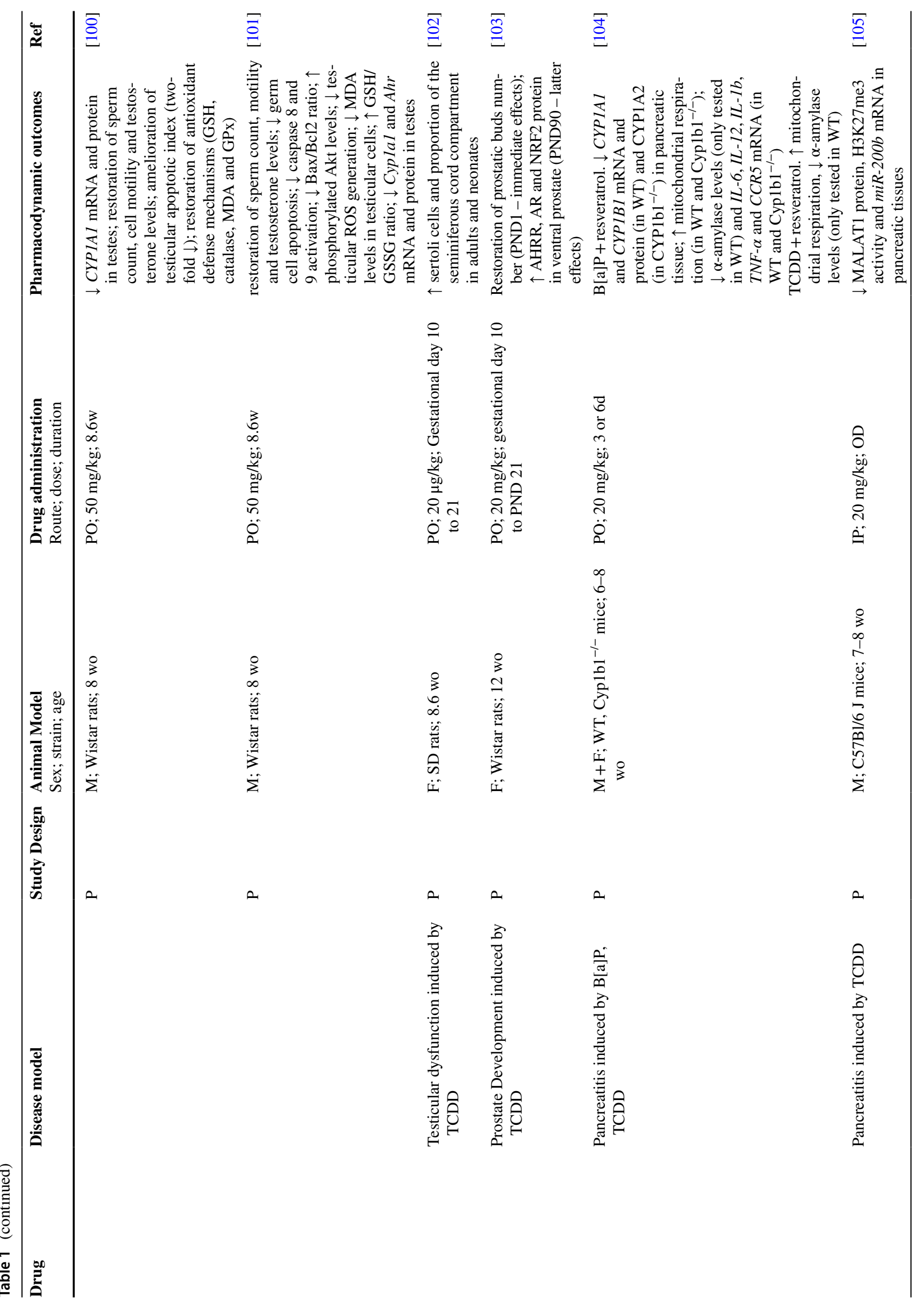




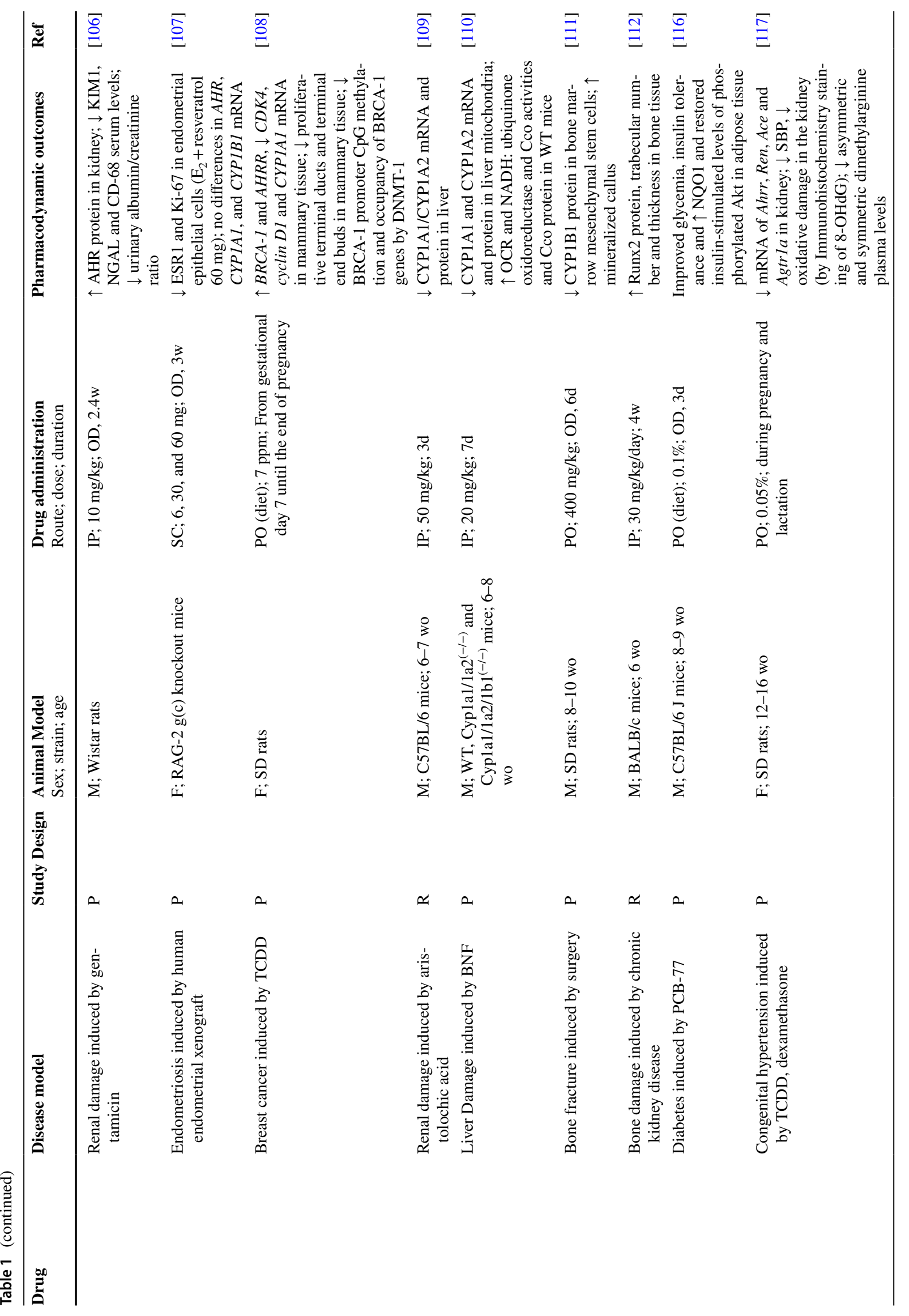




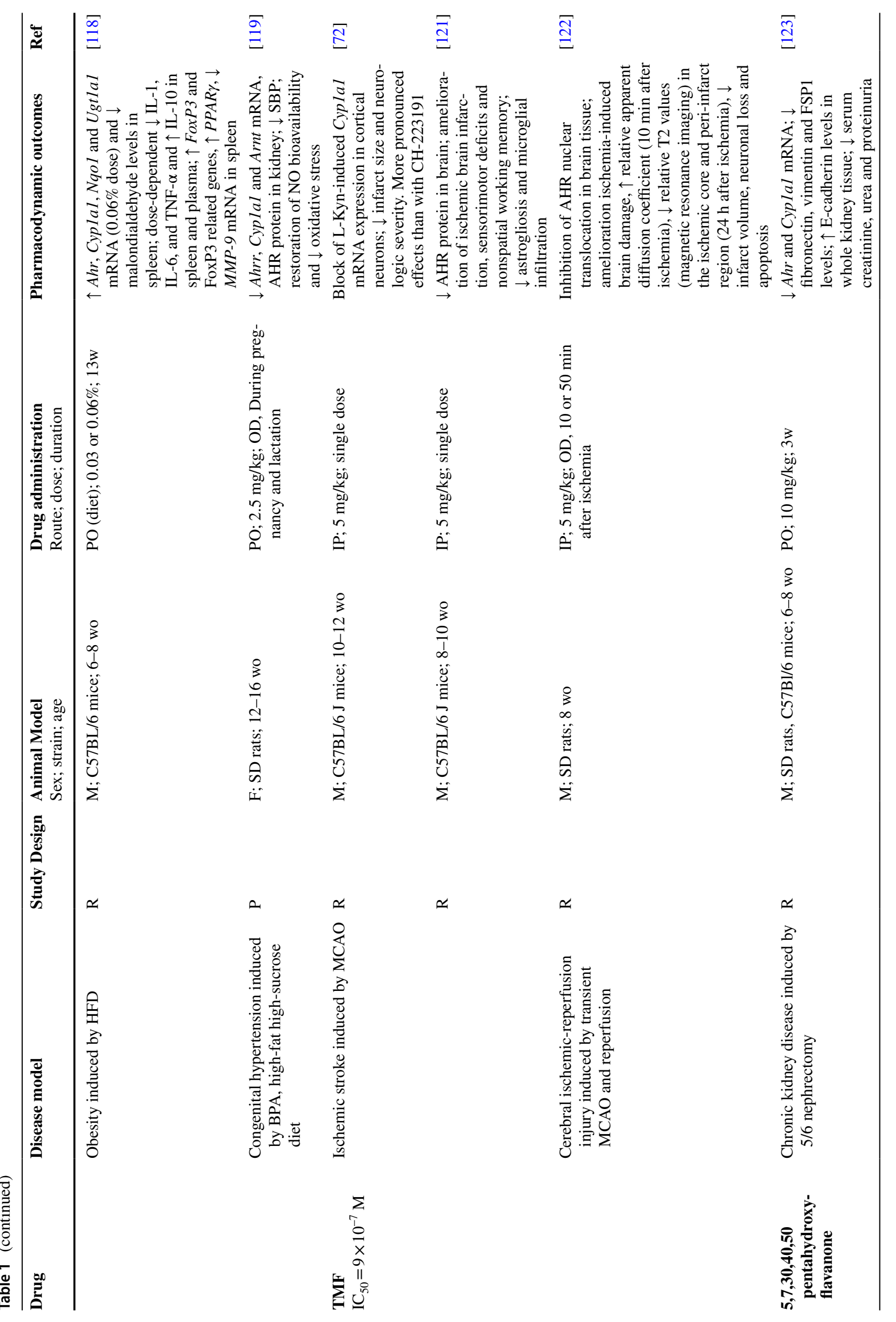




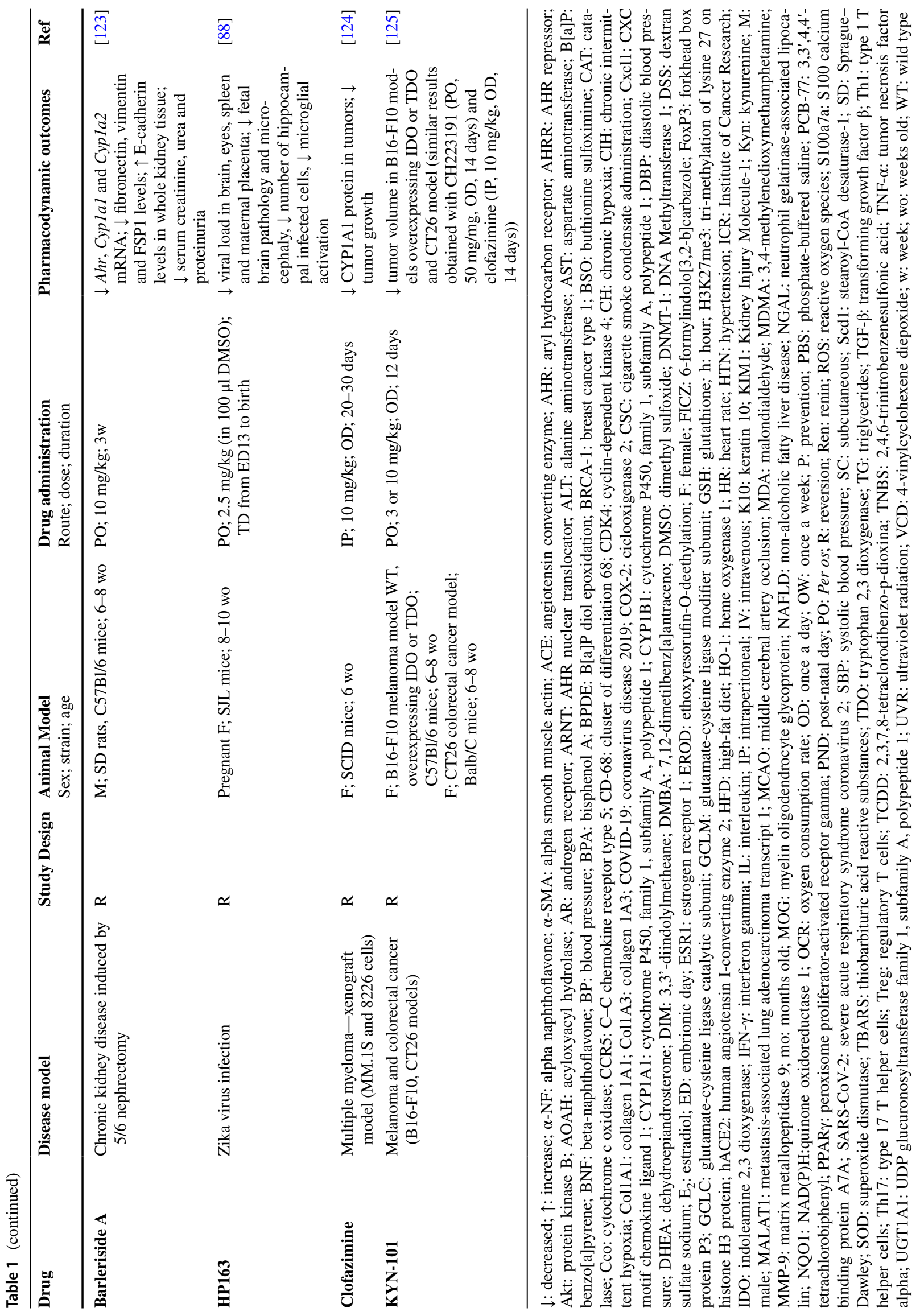




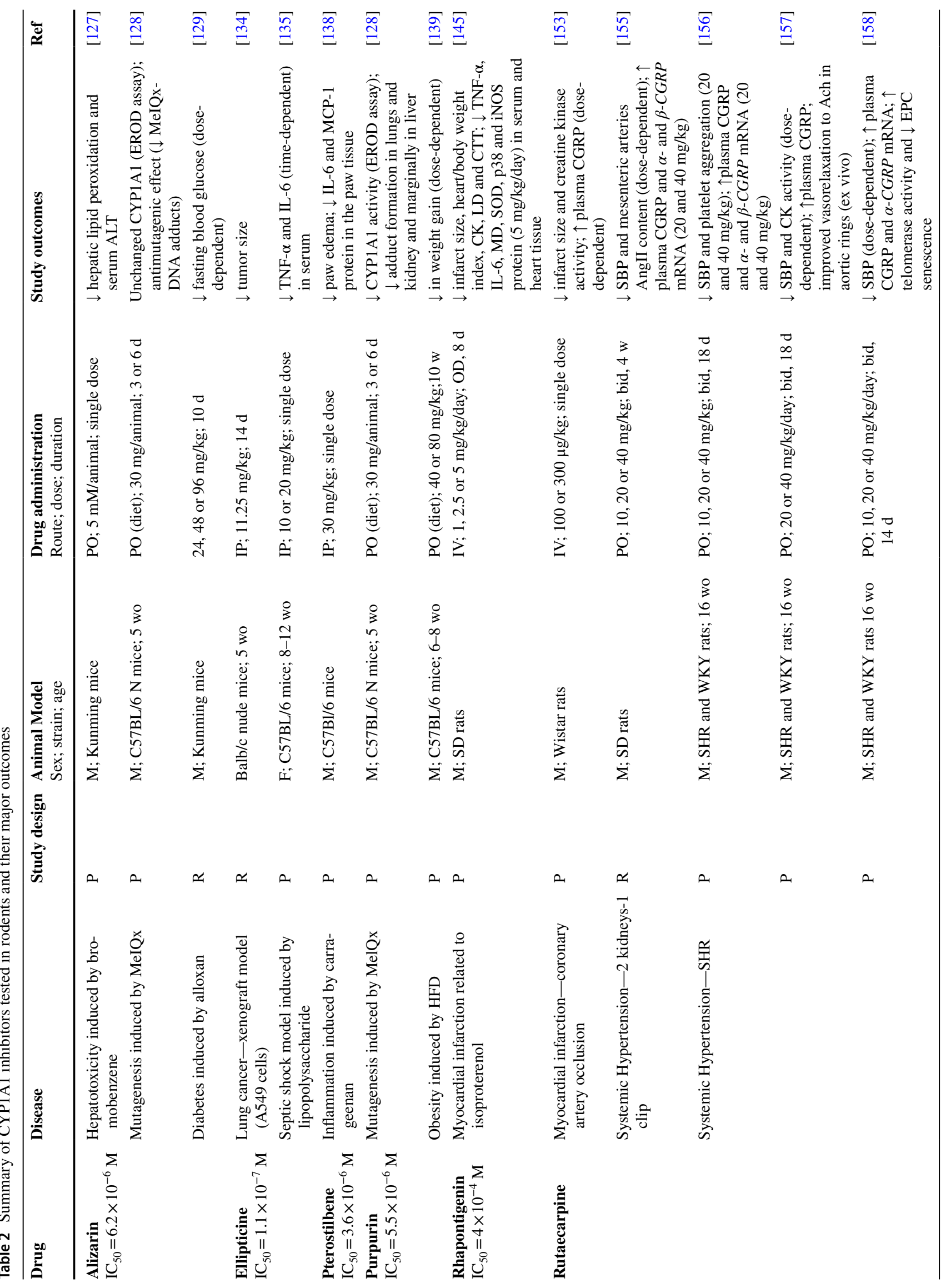




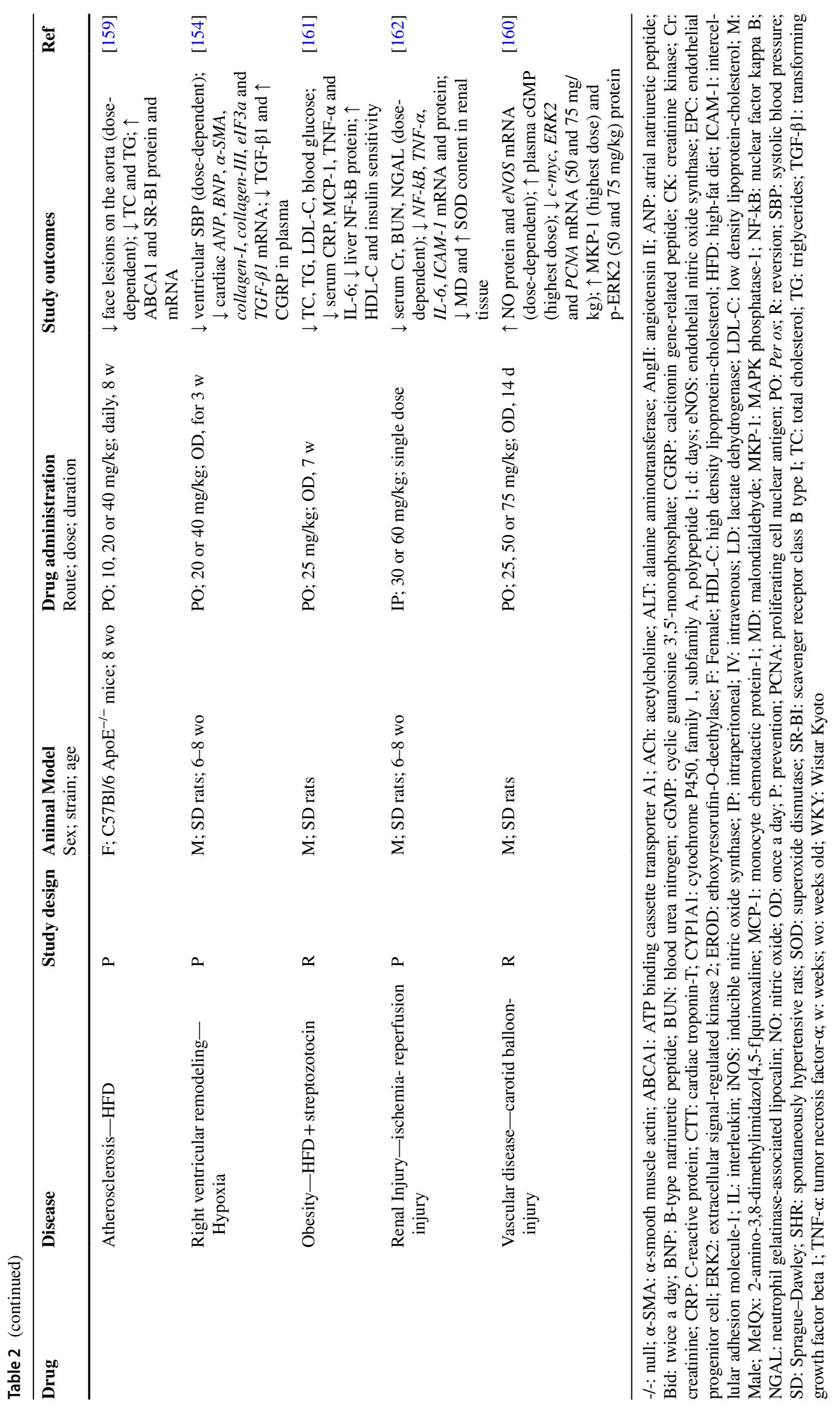


Fig. 2 AHR antagonists and CYP1A1 inhibitors used in vivo. Chemical structures of AHR antagonists (A) and non-selective CYP1A1 inhibitors $(\mathbf{B})$
A

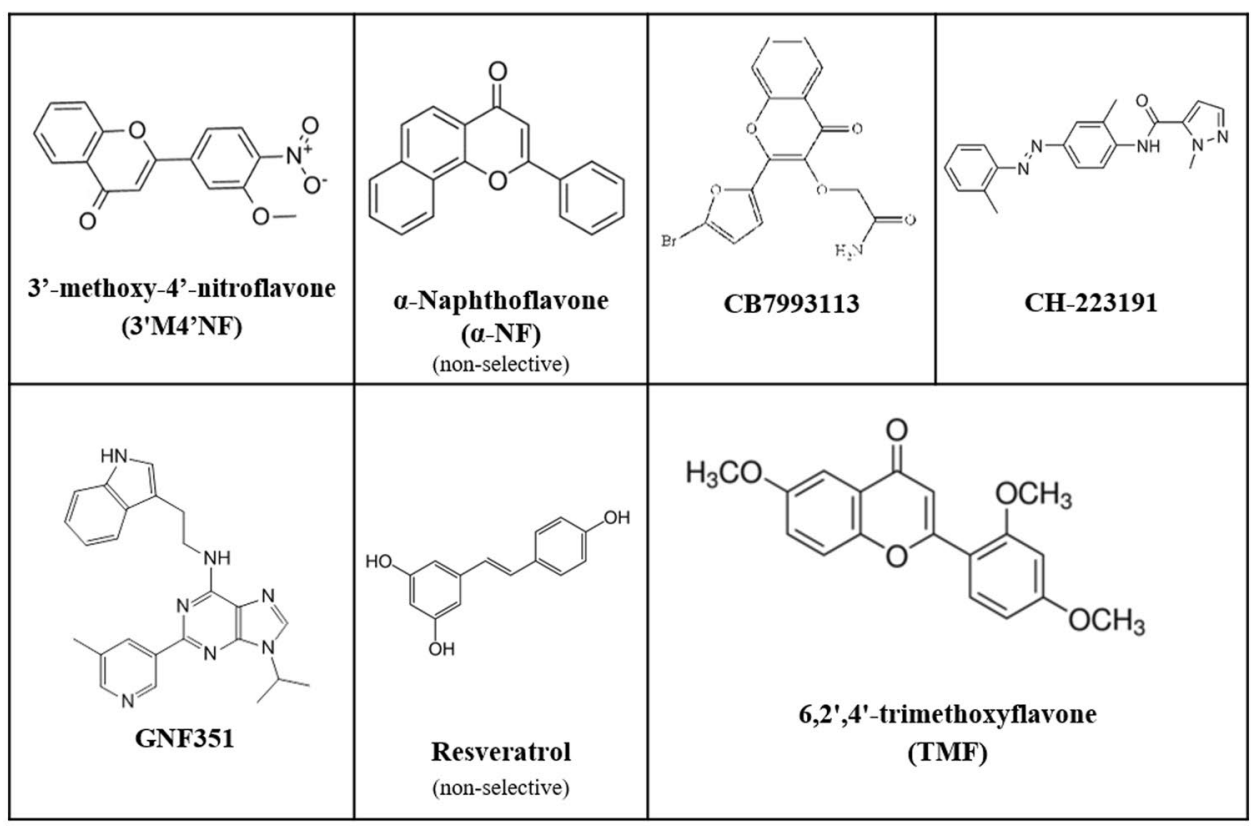

B<smiles>COc1cc(C=Cc2ccc(O)cc2)cc(OC)c1</smiles>

allow the activation of the alternative pathway (Fig. 1), for which the AHR target gene is the paraoxonase 1 (PON-1) [37].

\section{CYP1A1 inhibitors}

Cytochrome P450, family 1, subfamily A, polypeptide 1 (CYP1A1) is a xenobiotic metabolizing enzyme involved in the phase I metabolism of several exogenous (e.g., Sudan I, caffeine, $\mathrm{B}[\mathrm{a}] \mathrm{P}$ ) and endogenous (estrogens, estradiol, progesterone, testosterone, pregnenolone, melatonin arachidonic acid) compounds [38, 39]. CYP1A1 is responsible for ROS production (e.g., superoxide anion, hydrogen peroxide, and hydroxyl radical derived from the oxygen and electron transfers that occur during the CYP reaction cycle) [40] and for the metabolic activation of procarcinogens (e.g., $\mathrm{B}[\mathrm{a}] \mathrm{P}$, estrogens) [41-45]. AHR signaling is constitutively activated, and the expression of CYP1A1 gene is almost exclusively regulated by AHR [46], allowing this gene to be considered the hallmark of its activation. Thus, CYP1A1 gene is a good indicator to associate AHR pathway to disease state and to evaluate the efficacy of the AHR antagonists abrogating this pathway. In 
addition, CYP1A1 inhibitors (Fig. 2B) represent important tools to clarify the deleterious effects of an increased activation of AHR-adaptive/canonical pathway. Unfortunately, there are no selective inhibitors for this CYP450 isoenzyme up to date. Importantly, most of the presented compounds were classified as CYP1A1 inhibitors in vitro, particularly using the ethoxyresorufin-O-deethylation (EROD) assay (measures CYP1A1/A2 activity) with recombinant CYP1A1 and NADPH fractions [47] $\left(\mathrm{IC}_{50}\right.$ values in Table 2). However, when tested in vivo, some of these compounds revealed AHR agonist activity, acting as CYP1A1 inducers and allowing an increase in CYP1A1 transcription and activity. This is the case of rutaecarpine (see section of CYP1A1 inhibitors). A plausible explanation is that not all in vitro models are suitable to study enzyme induction [48, 49]; EROD activity does not measure only CYP1A1 activity [49]; and most of the compounds are not highly selective for CYP1A1 (see section of CYP1A1 inhibitors). Moreover, enzyme inhibition effects by direct binding to the enzyme are more rapid and short than induction effects. Induction effects take longer to be observed and are long lasting compared to enzyme inhibition. Another possibility relies on the fact that some CYP1A1 substrates (like FICZ) can also be AHR ligands. As such, the inhibition of the metabolism of CYP1A1 can lead to an increase of the concentrations of these compounds and, therefore, to an increase in AHR-mediated CYP1A1 activation. This may be also dependent on the dose and the number of doses administered and might justify differences among studies. Thus, with increased evidence that is becoming available, it is plausible that some compounds are, in fact, not direct AHR ligands but indirect AHR modulators (e.g., CYP1A1 inhibitors). We decided to include the compounds that have been classified in vitro as CYP1A1 inhibitors and to discuss in vitro/in vivo controversies in literature, highlighting the need for more in vivo evidence and particularly to understand the underlying mechanisms of AHR-CYP1A1 modulation in vivo by CYP1A1 inhibitors.

\section{Pharmacological effects of the antagonists of AHR canonical pathway}

\section{3'-methoxy-4'-nitroflavone}

3'-methoxy-4'-nitroflavone (3'M4'NF) impairs AHR nuclear translocation, plausibly by hindering the dissociation of HSP90 from the chaperone complex [50]. Nazarenko and collaborators (2001) used transgenic C57B1/6 J male mice that express $\beta$-galactosidase in response to AHR agonists (DRElacZ mice) and showed that TCDD-induced AHR activation was abrogated by $3^{\prime} \mathrm{M} 4^{\prime} \mathrm{NF}$ at the liver but not at the lung, highlighting an organ-specific difference in $3^{\prime} \mathrm{M} 4{ }^{\prime} \mathrm{NF}$ effects. In addition, CYP1 A1 protein levels at the lungs showed a moderate increase in mice treated exclusively with $3^{\prime} \mathrm{M} 4{ }^{\prime} \mathrm{NF}$, which might be suggestive of a partial agonist action for this compound [34]. This compound has been used in vivo to investigate the relation of AHR to genotoxicity by environmental pollutants [51,52] and ultraviolet radiation-induced immunosuppression [53] (Table 1).

\section{a-Naphthoflavone}

$\alpha$-Naphthoflavone ( $\alpha$-NF), also known as 7,8-benzoflavone or 2-phenyl-4H-benzo[h]chromen-4-one, is a synthetic flavone considered a putative chemopreventive agent due to its non-selective activities as inhibitor of aromatase (CYP19A1 [54]) and also as modulator of AHR and of several CYP450 enzymes [35, 55]. $\alpha$-NF has been described as a partial agonist/antagonist of AHR [36] and as a competitive inhibitor of CYP1 family, namely of CYP1A1 [56], CYP1A2 [57] and CYP1B1 [58], rendering its common use in xenobiotic biotransformation studies. Moreover, $\alpha-\mathrm{NF}$ is an allosteric activator of CYP3A4 [59]. The preventive effect of this compound was investigated on chemical exposure (ovotoxicity and teratogenicity) [60,61], metabolic (obesity and non-alcoholic fatty liver disease) [62-64], and autoimmune diseases (psoriasis) [65] (Table 1).

\section{Cardiometabolic diseases}

Evidence suggested dose- and sex-dependent effects of $\alpha-\mathrm{NF}$ in obesity-related features (liver status and fat mass) [62-64] (Table 1).

A preventive protocol showed that $\alpha-\mathrm{NF}$ ( $3 \mathrm{mg} / \mathrm{kg} / \mathrm{day}$ ) impacted high-fat diet (HFD)-induced obesity in male mice [62]: it reduced the gain/increase in body mass, fat mass, triglycerides, and polyunsaturated fatty acids. In addition, $\alpha-\mathrm{NF}$ ameliorated liver steatosis (assessed by a histologic decrease in fat vesicles) but caused hepatomegaly.

A higher dose of $\alpha-\mathrm{NF}$ ( $90 \mathrm{mg} / \mathrm{kg} /$ day) was administered to male and female mice of two strains, the $\mathrm{C} 57 \mathrm{Bl} / 6 \mathrm{~B} 6$ and the C57B1/6.D2, which express a ligand-binding domain of AHR with higher and lower affinity, respectively. In addition to dose-dependent effects, it was possible to observe sexand AHR genotype-dependent differences with long-term $\alpha$-NF administration. Both AHR genotypes and sexes presented better fat mat-related outcomes upon $\alpha$-NF treatment, although there were differences in the degree of response, dependent on the strain and sex [63]. $\alpha$-NF has also reduced steatosis in both sexes and genotypes. However, hepatomegaly was present in all $\alpha$-NF mice treated independently of the diet, especially in the female groups [63].

In addition, in male mice on a HFD-induced non-alcoholic fatty liver disease (NAFLD), the administration of $\alpha-\mathrm{NF}$ reduced liver damage, attenuated oxidative stress, and diminished insulin resistance in a dose- and AHR-dependent manner [64]. 


\section{Autoimmune diseases}

Using a mice model of skin inflammation (Aldara-induced psoriasis), Kyoreva and colleagues (2021) investigated the $\alpha-\mathrm{NF}$ effects and observed decreased CYP1A1 activity, epidermis thickness, and levels of several proinflammatory mediators, together with an increase in keratinocyte differentiation markers [65].

\section{CB7993113}

Parks and collaborators (2014) discovered CB7993113 (2-((2-(5-bromofuran-2-yl)-4-oxo-4H-chromen-3-yl)oxy) acetamide) by ligand shape-based virtual modeling techniques. The compound showed no partial AHR agonist effect [66]. CB7993113 is a competitive antagonist of AHR (upon activation by $\beta$-naphthoflavone (BNF) or TCDD) and prevents AHR nuclear translocation as its primary mechanism of action. This compound is slightly less effective than CH-223191 (see CH-223191) in blocking the AHRCYP1A1 activation in the liver by TCDD [66].

CB7993113 prevented bone marrow cell ablation (Table 1), in 7,12-dimetilbenz[a]antraceno (DMBA)-induced myelosuppression in mice [66].

In pharmacokinetic experiments in mice, CB79993113 was administered intraperitoneally or orally (single dose of $50 \mathrm{mg} / \mathrm{kg}$ ), and serum was collected 4,8 , and $16 \mathrm{~h}$ after treatment. Pharmacokinetic analyses revealed that this antagonist was readily absorbed $1 \mathrm{~h}$ after both oral and intraperitoneal administration. However, serum concentrations were twice higher $1 \mathrm{~h}$ after intraperitoneal than oral administration, revealing a high oral first-pass effect. The compound presented a half-life of $4 \mathrm{~h}$ [66].

\section{CH-223191}

CH-223191 (1-methyl-N-[2-methyl-4-[2-(2-methylphenyl) diazenyl]phenyl-1H-pyrazole-5-carboxamide) is the most well-known AHR antagonist [33], and its effects have been widely investigated in diverse models of disease (Table 1), including interstitial cystitis [67]. CH-223191 does not stimulate AHR-dependent transcription even at higher doses, thus being described as a pure antagonist. This compound also displays no affinity for the estrogen receptor, as some other AHR antagonists do, and displays no cytotoxic properties [68]. Like CB7993113, this compound prevented DMBA-induced bone marrow cell ablation [66].

CH-223191 preferentially avoids AHR activation by TCDD and other related HAHs than BNF, PAHs, flavonoids, or indirubin. Other CH-223191 derivatives presented similar antagonistic properties at blocking TCDD-induced AHR nuclear translocation and similar affinity to AHR, but no other pharmacological properties for these derivatives were evaluated [69]. To the best of our knowledge, there are no pharmacokinetic studies of CH-223191 in wild-type animals nor in models of disease. Moreover, long-term studies using CH-223191 are also limited, plausibly due to the elevated cost of this drug as referred elsewhere [62].

\section{Gastrointestinal tract diseases}

Gastrointestinal toxicity of CH-223191 might be anticipated [70]. In fact, $\mathrm{CH}-223191$ worsened the intestinal fibrosis induced by trinitrobenzene-sulfonic acid (TNBS) [70]. CH-223191 administration promoted an upregulation of the fibrosis markers collagen 1A1 (Col1 A1) and 3A1 (Col3A1) and alpha smooth muscle actin ( $\alpha$-SMA), in opposition to the effect of the administration of the AHR agonist FICZ. These results suggest the role of AHR activation as a negative regulator of profibrotic signals in the gut [70].

Accordingly, other studies have shown that CH-223191 might worsen colitis in a murine model. Ulcerative colitis was induced in mice by drinking dextran sulfate sodium (DSS), whereas the AHR agonist baicalein displayed an effective anti-colitis effect. This effect was associated with an anti-inflammatory effect promoted by regulatory $\mathrm{T}$ cells (Treg) cell differentiation and Type $17 \mathrm{~T}$ helper-Th17/Treg balance. CH-223191 administration avoided the amelioration of symptoms of colitis associated with baicalein and abrogated the baicalein-dependent restoration in the balance between Th17 and Treg cells. Moreover, CH-223191 prevented the anti-inflammatory effect of AHR activation by precluding the decrease of the proinflammatory cytokines tumor necrosis factor a (TNF-a) and interleukins 6 (Il-6) and 17 (Il-17) and the increase of anti-inflammatory cytokines (transforming growth factor-TGF- $\beta$ and IL-10) [71].

\section{Cardiometabolic diseases}

In vivo studies showed $\mathrm{CH}-223191$ pharmacodynamic properties in models of ischemic stroke [72,73], obesity [62, 63], and arterial hypertension related to obstructive sleep apnea [30], among others (Table 1).

The cardiovascular and neuroprotective effects of CH-223191 were shown in an ischemic stroke model of middle cerebral artery occlusion. Upon this procedure, mice presented increased activation of the AHR-CYP1A1 axis and increased AHR protein in neurons of the damaged area. Intraperitoneal administration of the AHR antagonist CH-223191 (10 mg/kg) decreased infarct size and neurologic damage severity [72]. Similar results were obtained in a more recent study. Administration of $\mathrm{CH} 223191$ (intraperitoneal, $10 \mathrm{mg} / \mathrm{kg}$ ) $1 \mathrm{~h}$ before middle cerebral artery occlusion prevented AHR and CYP1A1 overexpression in brain cortex and striatum (mRNA levels). Moreover, neuroinflammation was decreased, namely by suppressing the 
upregulation of TNF-a, IL-1 $\beta$, and cyclooxygenase 2 (COX2 ) in those tissues. Lipid peroxidation was also reduced in the cortex (thiobarbituric acid-reactive substance assay). Consequently, $\mathrm{CH}-223191$ reduced vasogenic edema, infarct size, and neurological severity [73].

Using a model of obesity induced by a HFD (same study presented in "Cardiometabolic diseases" [62]), CH-223191 reduced body mass gain and fat mass and ameliorated liver steatosis (as assessed by a histologic decrease in fat vesicles). Importantly, and in contrast to $\alpha-\mathrm{NF}$, animals treated with $\mathrm{CH}-223191$ showed no hepatomegaly [62]. Dietinduced obesity was also prevented by the use of the same dose of CH-223191 in female mice [63].

Coelho and his team (2020) established a mechanistic link between AHR and systemic hypertension induced by chronic intermittent hypoxia. Chronic intermittent hypoxia is a pivotal clinical feature present in obstructive sleep apnea, being responsible for most of its comorbidities, namely arterial hypertension that is often resistant among these patients. Using a moderate paradigm of chronic intermittent hypoxia mimicking mild obstructive sleep apnea, the authors found an increased activation of AHR-CYP1A1 axis (increased Ahr and Cyplal mRNA), particularly in kidney when hypertension was already established. Moreover, AHR pharmacological blockade by $\mathrm{CH}-223191(5 \mathrm{mg} / \mathrm{kg})$ was able not only to prevent, but specially to revert fully established hypertension [30].

\section{Lung diseases}

This AHR antagonist has been studied in pulmonary diseases as well. Oral administration of CH-223191 (8 mg/kg) to Wistar rats reversed pulmonary hypertension induced by the combination of a vascular endothelial growth factor receptor antagonist and AHR agonist (Sugen 5416) and chronic sustained hypoxia, without effects in systemic blood pressure and heart rate [74]. CH-223191 totally reverted the increase in ARNT levels in diseased lungs and partly reverted AHR and CYP1A1 pulmonary overexpression [74], pointing to AHR inhibition as a potential pulmonary hypertension treatment (Table 1).

It is widely known that cigarette smoking contains AHR ligands [75], making its link plausible with exacerbated inflammatory responses associated with smoking. However, AHR activation seems to attenuate smoke-induced pulmonary inflammatory responses, in particular neutrophilia. When mice were exposed to cigarette smoke, the group of animals receiving $\mathrm{CH}-223191$ intraperitoneally $(50 \mu \mathrm{g})$ contained an increased number of total cells and particularly neutrophils in the bronchoalveolar fluid, compared to the vehicle (DMSO) group. This pattern was also observed when exposing $\mathrm{AHR}^{-1-}$ mice to cigarette smoke, thus highlighting that AHR activation by smoking is important to limit smoke-induced neutrophilia. Nevertheless, most of the cytokines produced by neutrophils, macrophages, and lymphocytes were increased upon exposure to the cigarette smoking, although no significant differences between the group treated with $\mathrm{CH}-223191$ and the vehicle group were observed, meaning an independent effect of AHR activation occurring in the increased cytokine production of the bronchoalveolar fluid [76].

\section{Immune-mediated diseases}

The role of the AHR in inflammatory and autoimmune diseases, such as rheumatological diseases, has been increasingly studied, in particular using CH-223191 as a proofof-concept antagonist (Table 1). Undesirable effects of $\mathrm{CH}-223191$ in the bone tissue might be anticipated. In a collagen-induced arthritis model in rats, the AHR agonists tetrandrine and 3,3'-diindolylmetheane (DIM) inhibited osteoclastogenesis and bone destruction. AHR blocking by $\mathrm{CH}-223191$ (oral, $5 \mathrm{mg} / \mathrm{kg}$ ) almost abolished the protective effect of these AHR ligands, thus emphasizing the need of more studies to better characterize the pharmacology of AHR antagonists in bone [77].

Systemic sclerosis is an autoimmune disease characterized by the presence of fibrosis in several organs for which there is no effective treatment. AHR signaling has been implicated in fibrotic processes in multiple tissues, such as liver, dermis, and vascular structures, although the exact extent of this implication is yet unclear [78, 79]. In a murine model of skin sclerosis induced with bleomycin, the administration of the AHR agonist FICZ reduced collagen induction (a-SMA protein) and dermal thickness. These protective effects were inhibited by $\mathrm{CH}-223191$ subcutaneous administration $(10 \mu \mathrm{g})$, hence showing that AHR signaling controls scleroderma fibrosis [80].

Another group employed the indole DIM, a dietary ligand of AHR, and $\mathrm{CH}-223191$ to assess immunomodulatory functions of the AHR in a murine model of experimental autoimmune encephalomyelitis (EAE). DIM improved the clinical scores of EAE and suppressed the production of proinflammatory cytokines, whereas $\mathrm{CH}-223191$ (intravenous) abolished that effect, aggravating the clinical score when compared to DIM-treated animals, and promoting the production of TNF-a, IL-6, IL-1 $\beta$, IL-17A and IFN- $\gamma$ cytokines, while decreasing IL-10 and TGF- $\beta$. Animals treated with CH-223191 also showed a great proportion of Th17 and Type $1 \mathrm{~T}$ helper (Th1) cells, suggesting an immunomodulatory effect AHR-dependent on regulatory T cells [81].

The modulatory effect of AHR over T cells, namely $\mathrm{CD} 4+\mathrm{T}$ cells, may rely on redox homeostasis. Mice were treated with FICZ, buthionine sulfoximine (BSO), an inhibitor of the synthesis of the antioxidant glutathione, $\mathrm{N}$-acetylcysteine, an antioxidant, or $\mathrm{CH}-223191$. The 
expression of redox-related genes was assessed in splenocytes. FICZ and BSO increased the mRNA expression of several redox-related genes, such as heme oxygenase 1 (HO-1), glutamate-cysteine ligase catalytic subunit (GCLC), and glutamate-cysteine ligase modifier subunit (GCLM), whereas CH-223191 + FICZ co-treatment or NAC prevented those overexpressions. The AHR agonist FICZ increased the total CD4 + cells count and Th1 cells, while a dose-dependent decrease in Treg cells was determined. Nevertheless, the simultaneous administration of $\mathrm{FICZ}+\mathrm{CH}-223191+\mathrm{NAC}$ was responsible for enhancing Treg production, together with Th1 and Th17 cells with a high dose, and for decreasing Treg and increasing Th2 and Th17 cells in a lower dose. Replacing NAC for BSO in the latter scenario increased Th1 and Th17 cells. Such results led to the conclusion that AHR activation interferes with the fate of $\mathrm{T}$ cells, influenced by redox alterations [82].

\section{Hormonal disorders}

A recent work by a Japanese group aimed to study how the relationship between endoplasmic reticulum stress in granulosa cells from the ovary and AHR could contribute to polycystic ovary syndrome (PCOS). Using a murine model of PCOS induced by dehydroepiandrosterone (DHEA), they observed no cyclicity in the estrous cycle and alteration in ovarian morphology. CH-223191 (10 mg/kg) subcutaneous administration restored the loss of cyclicity and ovarian morphology with a decrease in atretic antral follicles, which occurred simultaneously with a downregulation in the AHRCYP1B1 axis in the granulosa cells [83].

\section{Brain injury}

Apart from the aforementioned applications of $\mathrm{CH}-223191$ in the context of ischemic stroke, this antagonist has also been used to investigate mechanisms of brain diseases and neurotoxicity. To assess how 3,4-methylenedioxymethamphetamine (MDMA), a psychostimulant drug used for recreational purposes, could interfere with Kyn and AHR activity and hence impact on serotonergic neurotoxicity, a group of investigators treated rats with MDMA and CH-223191. MDMA was able to increase Kyn levels and AHR activity, in the short term, in the hippocampus. $\mathrm{CH}-223191(10 \mathrm{mg} / \mathrm{kg})$ intraperitoneal treatment potentiated the MDMA-induced serotonergic neurotoxicity as shown by a lower density of serotonin transporter in the cotreated group (MDMA + CH-223191), while DIM (AHR agonist) treatment showed an opposite scenario of partial prevention on the MDMA-associated serotonergic damage. Therefore, it appears that AHR and Kyn may play a role dampening MDMA-induced neurotoxicity [84].

\section{Infectious diseases}

The multiplicity of actions attributed to $\mathrm{CH}-223191$ treatment involves microbial diseases as well. Host defenses against fungal infections like paracoccidioidomycosis (PCM) rely on the immunoprotective Th1 and Th17 cells, while Th2/Th9 cell predominance is implicated in infection's progression [85]. Among several players implicated in this immune network, AHR is gaining prominent attention, namely due to its influence on Th17 and Treg cells [86]. In fact, in a murine model of PCM induced by intratracheal infection of the fungus Paracoccidioides brasiliensis, administration of AHR agonists, either FICZ or Kyn, decreased pulmonary and hepatic fungal loads and the number of activated lung myeloid cells $(\mathrm{CD} 11 \mathrm{c}+)$. However, CH-223191 treatment showed the opposite scenario, increasing fungal load (only in the lungs) and the number of the pulmonary CD11c + cells, both at short and long term after infection ( $96 \mathrm{~h}$ and 2 weeks). In addition, $\mathrm{CH}-223191$ led to a reduced number of $\mathrm{CD} 11 \mathrm{c}+$ cells expressing intracellular cytokines (IL-12, IL-1 $\beta$, IL-6, and TGF- $\beta$ ) and also indoleamine 2, 3-dioxygenase 1 (IDO-1) and AHR, together with an increase in cells expressing TNF- $\alpha$. The number of $\mathrm{CD} 11 \mathrm{c}+$ cells expressing membrane (IAb, CD80, CD86) markers was also increased. CH-223191 also augmented the migration of myeloid dendritic cells to the lungs and promoted the expansion of Th17 lymphocytes associated with concomitant reduction of Treg cells, Th1, and Th22 $[87,88]$. The results strongly suggest that fungal infections can be modulated by AHR signaling, unveiling new perspectives to treat these infections.

The implications of CH-223191 and AHR pathway are also seen in viral diseases. A study concerning Zika virus classified AHR as a host-enabling replication factor for the virus. Indeed, AHR signaling is activated upon Zika virus infection, via Kyn production. SJL pregnant mice were infected with Zika, whose consequences mimic several features of congenital Zika, especially microcephaly and cortical brain lesions. CH-223191 (5 mg/kg) was administered, via intraperitoneal, in a nanoliposomal formulation, enabling an increase in its solubility and biodistribution. The antagonist suppressed AHR signaling, decreasing CYP1B1 expression. CH-223191 ameliorated fetal intrauterine growth restriction, microcephaly, and reduced fetal brain pathology (thicker cortical plates and reduced ventricle sizes) while reducing brain and splenic viral load. Sustaining these structural observations, molecular analysis using RNA sequencing and polymerase chain reaction (PCR) analysis observed a decrease in genes associated with apoptosis, tissue damage, and autophagy upon CH-223191 treatment, simultaneously with an upregulation of inflammatory pathways like NF-kB and IFN-1, suggesting that AHR blocking in the context of Zika virus enhances immune and inflammatory mechanisms 
to control viral replication and pathogenesis and unraveling a potential antiviral approach [89].

The effectiveness of the antiviral effect of CH-223191 has also been investigated in COVID-19 (coronavirus disease 2019), the pandemic disease caused by the severe acute respiratory syndrome coronavirus 2 (SARS-CoV-2). AHR was activated by either IFN- $\beta$ or IFN- $\gamma$, in an IDO-Kyn fashion, in the presence of SARS-CoV-2 infection. Consequently, mucins were upregulated in alveolar pulmonary epithelial cells, promoting a pro-hypoxic state, thus aggravating COVID-19-associated respiratory disease. The intratracheal administration of $\mathrm{CH}-223191$ ameliorated the IFNinduced impairment of respiratory function and prevented the expression of mucins in the lungs of IFN-treated mice. Furthermore, upon infection of a transgenic murine line (human angiotensin-converting enzyme 2-hACE2 transgenic) with SARS-CoV-2, CH-223191 intravenous treatment reduced the expression of several types of mucins and the disease severity in the lungs, highlighting the potential of CH-223191 as an effective strategy against COVID-19 [90].

\section{GNF-351}

GNF-351 (N-(2-(3H-Indol-3-yl)ethyl)-9-isopropyl-2-(5methyl-3-pyridyl)-7H-purin-6-amine) is an AHR antagonist without partial agonist activity that has been used to characterize AHR signaling and AHR tissue specificities in vitro [91]. While no studies addressing its pharmacological actions in in vivo models of disease could be found, we herein included an in vivo study dedicated to GNF-351 pharmacokinetics [92]. Upon oral administration in mice $(5 \mathrm{mg} / \mathrm{kg}$ of body weight), GNF-351 was detected in serum at several time points up to $6 \mathrm{~h}$ after drug administration. At $24 \mathrm{~h}$ postadministration, the compound was found in feces, but not in urine. Reduced intestinal absorption and extensive intestinal biotransformation of GNF-351 were supported by several phase I metabolites of GNF-351 exclusively detected in feces. Accordingly, this drug prevented the AHR-agonist BNFinduced mRNA expression of Cyplal at the ileum and colon, but not at the liver. These results emphasize the relevance of in vivo studies to better understand absorption, tissue distribution, and impact of AHR-CYP1A1 activation in different tissues. Likewise, this study suggests that GNF-351 might be a useful inhibitor of the AHR signaling in the distal intestinal tract [92] with a minor systemic impact. However, GNF-351 effects remain to be investigated in a disease model.

\section{Resveratrol}

Resveratrol (3,4',5-trihydroxy-trans-stilbene) is a naturally occurring polyphenol, commonly found in the skin of grapes, with antioxidant activity and free-radical scavenging properties (reviewed by [93]). Many mechanisms of action independent of AHR-CYP1A1 axis [94, 95] have been reported for resveratrol and several review papers were dedicated to the broad applications of resveratrol in pre-clinical and clinical contexts. For the sake of the scope of this review, we considered those studies that linked the pharmacological effects of resveratrol with the AHR canonical pathway. Although resveratrol inhibits the adaptive pathway of AHR, it also allows its nuclear localization and the binding to alternative xenobiotic response elements. The activation of this alternative pathway of AHR by resveratrol upregulates another set of genes associated with anti-inflammatory and antioxidant properties [37] (Fig. 1). In addition, resveratrol has also been described as a weak CYP1A1 inhibitor [96].

Resveratrol has been reported to protect from toxic effects on lung [97], thymus [98], testis [99-102], prostate [103], and pancreas $[104,105]$ related to environmental contaminants that are AHR activators. Resveratrol effect in drug iatrogenic effects [106], female related diseases [107, 108], kidney [109], liver [110], and bone disease [111, 112] was also evaluated (Table 1).

Regarding the pharmacokinetic properties (reviewed by Wenzel and Somoza [113]), resveratrol undergoes rapid first-pass metabolism, and it is mainly metabolized to its glucuronide and sulfate metabolites [114].

\section{Cardiometabolic diseases}

Polychlorinated biphenyls (PCBs) are persistent organic pollutants that have been associated with the development of type 2 diabetes. In vivo studies have demonstrated that PCBs accumulate in adipose tissue leading to its inflammation and impaired glucose homeostasis [115]. Resveratrol supplementation in the diet was able to prevent PCB-77-induced impairment of glucose and insulin tolerance in adipose tissue of mice. Additionally, resveratrol increased the mRNA expression of $\mathrm{NAD}(\mathrm{P}) \mathrm{H}$ quinone dehydrogenase 1 (NQO1) and restored insulin-stimulated levels of phosphorylated protein kinase B (Akt) in adipose tissue [116].

Female pregnant Sprague-Dawley rats were given the AHR activators dexamethasone (from gestational day 16 to 22) and/or TCDD (on gestational day 14 and 21 and postnatal day 7 and 14). When resveratrol was administered during pregnancy and lactation periods, the adult male offspring had a reduction in systolic blood pressure (SBP) of $20 \mathrm{mmHg}$ at 16 weeks of age, compared with the TCDD and dexamethasone maternal exposure groups. This effect was accompanied by less oxidative damage in the kidney and a decrease in renal AHRR expression. In addition, a blockade of renal renin-angiotensin system (RAS) was observed, including a decrease in expression of renin (Ren), angiotensin-converting enzyme (Ace), and angiotensin II receptor type 1a (Agtrla) as well as increased nitric oxide (NO) bioavailability [117]. 
Other studies have been investigating the beneficial effects of resveratrol in models of obesity [118] and arterial hypertension programmed by maternal exposure [119]. Hsu and his team investigated the ability of resveratrol to prevent arterial hypertension programmed by maternal exposure to bisphenol A (BPA) with or without high-fat high-sucrose diet during the entire period of pregnancy. Resveratrol reduced SBP $(10 \mathrm{mmHg})$ in the groups that also received BPA with and without high-fat high-sucrose diet. Immunohistochemistry staining 8-hydroxydeoxyguanosine in the kidney, used as an index of oxidative stress-derived DNA damage, showed that resveratrol therapy prevented the synergistic effect of high-fat high-sucrose diet and BPA exposure on oxidative stress damage. This compound also restored nitric oxide (NO) bioavailability through the increase of plasmatic L-arginine levels and protein levels of endothelial NO synthase (eNOS) and neuronal NO synthase (nNOS). Additionally, resveratrol decreased renal mRNA expression of Ahrr, Cyplal, and Arnt in the group receiving high-fat high-sucrose diet plus BPA [119].

\section{6,2',4'-trimethoxyflavone (TMF)}

TMF (6,2', $4^{\prime}$-trimethoxyflavone) has been described as a pure and selective AHR antagonist that effectively competes with TCDD [120]. Although there are several in vitro studies about the pharmacodynamic properties of TMF, its use in vivo is much less frequent (Table 1).

\section{Cardiometabolic and cardiovascular diseases}

TMF was used in a mice model of stroke induced by middle cerebral artery occlusion (same model described with CH-223191 [72]). TMF shared with CH-223191 neuroprotective properties but allowed a more pronounced reduction in infarct size and neurological severity in comparison with $\mathrm{CH}-223191$. More recently, Chen and collaborators (2019), using the same mice model of ischemic stroke, showed that AHR inactivation, through either TMF or conditional AHR knockout, reduced brain infarction. Similar effects were observed between TMF or AHR knockout: a decrease in astrogliosis and increase in neural progenitor cells. TMF reduced brain inflammatory markers after stroke (IL-1 $\beta$, IL- 6 and IFN- $\gamma$ ) and ameliorated animal's sensorimotor deficits and nonspatial working memory [121]. Later, Kwon and collaborators (2020) investigated the neuroprotective effects of TMF on cerebral ischemia-reperfusion injury. TMF was administered 10 or $50 \mathrm{~min}$ after ischemia but before reperfusion in a rat model of stroke induced by transient middle cerebral artery occlusion and reperfusion. At $24 \mathrm{~h}$ after ischemia, neuronal lesion was lower in the ischemic core and peri-infarct region (higher relative apparent diffusion coefficient and lower relative $\mathrm{T} 2$ values measured with magnetic resonance imaging) in the group that received TMF 10 min after ischemia. TMF administered 10 and $50 \mathrm{~min}$ after ischemia also reduced total infarct volume (magnetic resonance imaging) and the number of apoptotic cells (TUNEL staining). Immunofluorescence showed that TMF groups had lower AHR activity in the peri-infarct region [122].

\section{Novel AHR antagonists}

As the involvement of the AHR in the mechanism of a multiplicity of diseases has been increasingly advocated, the search for novel AHR antagonists has emerged as a hot topic. In fact, other compounds have been recently evaluated for their potential to antagonize the AHR signaling pathway (Table 1).

The flavonoids 5,7,30,40,50-pentahydroxy flavanone and barleriside A were recently evaluated in a CKD model. Both compounds decreased Ahr, Cyplal, and Cypla 2 mRNA levels in the kidney and reduced serum creatinine, urea, and proteinuria besides reducing fibronectin, vimentin, and FSP1 levels and increasing E-cadherin levels in the kidney [123].

HP163 is a monoalkylated amide of CB7993113. The intraperitoneal administration of HP163 $(2.5 \mathrm{mg} / \mathrm{kg})$ was evaluated against Zika infection. Similarly, to the observed results with $\mathrm{CH}-223191$, HP1763 reduced viral replication of Zika virus in mice, together with an amelioration in several clinical features associated with this infection, namely a reduction in microcephaly, in ventricular dilation and in cortical thinning [89].

Clofazimine is an antimycobacterial drug that showed anti-AHR activity in vitro (luciferase AHR reporter cell assay) [124]. The drug was tested in mice models of multiple myeloma. After tumor development, clofazimine $(10 \mathrm{mg} / \mathrm{kg}$, daily intraperitoneal injections) reduced tumor growth in a similar way as the antineoplastic drug bortezomib (1 mg/kg, biweekly intraperitoneal injections). Moreover, clofazimine decreased CYP1A1 protein levels in the tumor tissue [124].

KYN-101 (IC50 of $22 \mathrm{nM}$ in human HepG2 DREluciferase reporter assay) was tested in a melanoma model with physiological levels of IDO and tryptophan 2,3 dioxygenase (TDO) (B16WT) or overexpressing IDO (B16IDO) or TDO (B16TDO) and a colorectal cancer model overexpressing IDO in mice (CT26). KYN-101 (3 or $10 \mathrm{mg} / \mathrm{kg}$ ) led to tumor growth inhibition in B16IDO, B16TDO, and CT26 models but not in the B16WT model. Interestingly, similar results were obtained with the AHR antagonists CH-223191 (50 mg/mg) and clofazimine (IP, $10 \mathrm{mg} / \mathrm{kg}$ ) [125]. 


\section{Pharmacological effects of CYP1A1 antagonists}

\section{Alizarin}

The anthraquinone derivative alizarin (1,2-dihydroxyanthraquinone) is a food pigment described as a strong competitive inhibitor of CYP1A1 and CYP1A2 in vitro [126]. Alizarin also inhibits CYP1B1 and to a lesser extent CYP2A6 and CYP2E1 in vitro [126]. The antioxidant activity of alizarin was tested in a mice model of hepatotoxicity induced by bromobenzene. Pre-treatment with alizarin reduced the hepatic lipid peroxidation (thiobarbituric acid reactive substances (TBARS) assay) and serum aspartate aminotransferase (AST) levels [127]. CYP1A1 was not investigated.

Takahashi and collaborators (2007) evaluated the preventive effect of alizarin on MeIQx (amine 2-Amino3,8-dimethylimidazo[4,5-f]quinoxaline)-induced DNA adducts. C57BL/6 N male mice (5-weeks-old) were administered with the anthraquinone for 3 days followed by MeIQx alone or in combination with alizarin for 3 days. Pre-treatment with alizarin showed only a marginal reduction in the amount of adducts present in the lung and kidney. Moreover, the EROD assay (CYP1A activity) remained unchanged [128].

\section{Cardiometabolic and cardiovascular diseases}

Although the association with CYP1A1 was not investigated, Xu and co-workers (2019) showed that alizarin significantly decreased the levels of blood glucose, ameliorated lipid metabolism abnormalities, and decreased oxidative stress in a diabetic mice model upon administration of alizarin to male Kunming mice for 10 days [129].

\section{Ellipticine}

Ellipticine (5,11-dimethyl-6H-pyrido[4,3-b] carbazole) is a polyaromatic alkaloid that inhibits DNA topoisomerase II and forms covalent adducts with DNA. Ellipticine has been associated with anti-tumoral activity in vitro [130]. Ellipticine is metabolized mainly by CYP1A $1 / 2$ and CYP3A4 in vitro [131]. Although in vitro studies classify ellipticine as an inhibitor of CYP1A1, CYP2B, and CYP3A [132], in vivo evidence shifts to different conclusions. In a dose-response study, where male and female Wistar rats were treated with a single dose of 4,40 , or $80 \mathrm{mg} / \mathrm{kg}$ of ellipticine, Aimová and collaborators (2007) found sex differences in CYP1A1 content in the liver upon ellipticine administration, with males being more responsive to this compound. The lowest dose of ellipticine $(4 \mathrm{mg} / \mathrm{kg})$ originated a 26 -fold increase in CYP1A1 induction in males, differently to the moderate fivefold induction observed in females. Also, while in males, CYP1A1 induction correlated positively with ellipticine dose, in females, the maximum induction of CYP1A1 was attained with the intermediate dose $(40 \mathrm{mg} / \mathrm{kg})$. CYP1A1 protein and mRNA levels and activity were assessed in the lung, liver, and kidney of male rats, showing a clear induction of CYP1A1 in these organs. The middle dose induced the highest increase of mRNA levels in the lung (24-fold), followed by the kidney (tenfold) and the liver (fivefold) [133]. The effects of ellipticine on CYP1A1 activity were also evaluated in a time-response study. Animals were given a single dose of $80 \mathrm{mg} / \mathrm{kg}$ of ellipticine and sacrificed at four time points (2-224 days). CYP1A1 protein levels achieved their peak at day 2 , returned to basal levels at day 14 , and remained low until the end of follow-up [133].

More studies are needed to evaluate the effects of single and multiple dose administration of ellipticine on CYP1A1 in vivo. It also remains to be understood the mechanism by which ellipticine might induce CYP1A1 despite being described as a CYP1A1 inhibitor in vitro.

\section{Cancer}

Ellipticine reduced the tumor size and demonstrated its activity against cell proliferation in a model of non-small cell lung cancer [134] (Table 2).

\section{Infection}

Ellipticine effectively prevented inflammation in the endotoxic shock mouse model: there was a time-dependent reduction in the levels of TNF- $\alpha$ and IL-6 [135] (Table 2).

\section{Pterostilbene}

Pterostilbene is a cell-permeable stilbenoid, analog of resveratrol, originally derived from Pterocarpus marsupium. This compound has antioxidant, anti-proliferative, antiinflammatory, and hypoglycemic effects and is a very potent inhibitor of CYP1A1 in vitro [136]. Pterostilbene also inhibits CYP2C8 and UGT1A6 enzyme activities in vitro [137].

\section{Inflammation}

Pterostilbene prevented edema and inflammatory markers in a carrageenan-induced inflammation mice model [138].

\section{Purpurin}

Like alizarin, purpurin is an anthraquinone derivative and a food supplement inhibitor of CYP1A1 and CYP1A2 in vitro 
[126]. Purpurin also inhibits CYP1B1 and to a lesser extent CYP2A6 and CYP2E1 in vitro [126].

Using a mice model of hepatotoxicity induced by bromobenzene (see Alizarin and Table 2), purpurin showed a time-dependent decrease in the activity of CYP1A1 and the formation of MelQx-DNA adducts at the lungs, kidney, and marginally at the liver. Purpurin displayed a stronger inhibitory capacity for CYP1A1 than alizarin [128].

\section{Cardiometabolic and cardiovascular diseases}

Although CYP1A1 activity was not evaluated, an anti-obesity effect has been described for this compound: a dose-dependent reduction in weight gain [139].

\section{Rhapontigenin}

Rhapontigenin (3, 3', 5-trihydroxy-4'-methoxy-stilbene) is a hydroxystilbene derivative, with similar structure to resveratrol, derived from the roots of Rheum undulatum [140]. This compound proved to be a mechanistic based inhibitor of the human CYP1A1 in vitro [141]. Rhapontigenin also inhibits CYP3A4 and CYP2C9 [142]. Pharmacokinetic investigation in rats showed that rhapontigenin has a half-life of $3 \mathrm{~h}$ and is extensively glucuronidated and predominantly cleared by the liver $[143,144]$.

\section{Cardiometabolic and cardiovascular diseases}

While no relation with AHR signaling was investigated, rhapontigenin was associated with cardioprotective effects in a model of isoproterenol-induced myocardial infarction in male Sprague-Dawley rats [145]. Rhapontigenin pretreatment ameliorated infarct size and heart weight and reduced protein expression of cardiac markers such as creatine kinase (CK), cardiac troponin-T (CTT), and lactate dehydrogenase (LD). It also reduced protein expression of superoxide dismutase (SOD) and malonaldehyde (MD), IL-6, p38, inducible NO synthase (iNOS), and TNF- $\alpha$ [145].

\section{Rutaecarpine}

Rutaecarpine is a quinazolinocarboline alkaloid extracted from the fruit Evodia rutaecarpa and commonly found in herbal products [146]. Rutaecarpine is an example of a compound whose impact on CYP1A1 activation has been described with conflicting results in different studies. In vitro studies described the compound as a selective CYP1A1 inhibitor [147]. However, most of the in vivo evidence shows that rutaecarpine activates the AHR-CYP1A1 axis [148-151]. For instance, rutaecarpine increased EROD activity in the mice liver (sixfold) and hepatic CYP1A1 (western blot). This effect was not observed in the kidney, denoting organ differences in rutaecarpine modulation of CYP1A1 [148].

\section{Cardiometabolic and cardiovascular diseases}

The effects of rutaecarpine in vitro and in vivo that support its putative cardiovascular protective effect are reviewed elsewhere [152]. Rutaecarpine was investigated in in vivo models of myocardial ischemia-reperfusion injury [153], hypoxiainduced right ventricular remodeling [154], arterial hypertension [155-158], atherosclerosis [159], arterial remodeling [160], obesity [161], and renal ischemia-reperfusion injury [162]. Despite the beneficial cardiovascular effects observed, none of these works linked rutaecarpine action to the AHRCYP1A1 axis (Table 2).

\section{Overview of in vivo models' data}

This review highlights the paucity of in vivo data on the effects of AHR antagonists and CYP1A1 inhibitors in rodent models of disease, namely the compound's pharmacodynamics and tissue specificities for the mechanism of action; dose-effect dependence, AHR target genes, long term, and toxicity use.

The experimental design of these studies relied mostly on prevention protocols. Most studies administered the compound orally, but pharmacokinetic properties and dose-response relationship were barely evaluated. The age of animals varied from infant to young adult ages ( 3 to 12 weeks for mice and 6 to 16 weeks for rats), and there was no study in elderly. Sex differences were also underrepresented, as only $40 \%$ of the studies with the AHR antagonists and $10 \%$ of studies with CYP1A1 inhibitors were performed in female animals. The mean time of drug administration was $3.6 \pm 0.73$ and $3.2 \pm 0.44$ weeks for mice and rats, respectively. The longer period of administration was investigated for $\alpha-\mathrm{NF}$, an AHR antagonist, that was used for 26 weeks in a mice model of obesity (Tables 1 and 2).

\section{Clinical trials of AHR antagonists}

\section{Cancer}

AHR is a prognostic marker for aggressive cancer progression. High AHR levels have been found in many solid cancer types, including glioblastoma, ovarian cancer, and lung cancer. AHR might also have a direct effect on cancer at various stages: cell proliferation, tissue invasion, angiogenesis, inflammation, and metastasis. Blocking AHR is a promising approach to cancer immunotherapy (reviewed in [163-165]). 


\section{BAY2416964}

BAY2416964 represents an orally active antagonist of AHR with $\mathrm{IC}_{50}$ of $341 \mathrm{nM}$. An ongoing clinical trial with this small molecule is being conducted in patients with advanced cancer. By blocking AHR, it is expected that the oral administration of this small molecule will activate immune response against the tumor cells. This open-label, phase 1, first-in-human, dose-escalation, and dose-expansion study will evaluate the safety, tolerability, maximum tolerated or administered dose, pharmacokinetics, pharmacodynamics, and tumor response profile in patients with non-small cell lung cancer (NSCLC), head and neck squamous cell carcinoma (HNSCC), and colorectal cancer microsatellite stable (MSS). The compound was extracted from patent WO2018146010A1, and the study started in August 2019 and is at the recruiting phase [166].

\section{IK-175}

A phase 1, open-label, dose-escalation, and dose-expansion study of IK-175 is being conducted in patients with locally advanced or metastatic solid tumors and urothelial carcinoma.

This oral antagonist of AHR will be investigated in adult subjects diagnosed with any form of an advanced or metastatic solid tumor especially in patients who do not fully benefit from standard-of-care, including the checkpoint inhibitors.

Safety and tolerability of IK-175, to determine the recommended phase 2 dose, will be assessed in addition to pharmacokinetics, pharmacodynamics, and biomarkers of response [167].

\section{Duchenne muscular dystrophy}

\section{Ezutromid}

Ezutromid is a clinical stage compound for Duchenne muscular dystrophy patients. This compound was developed aiming at an increased expression of utrophin to mimic the missing dystrophin in this condition [168]. Ezutromid is an orally administered antagonist of AHR [169]. The drug undergoes extensive first-pass metabolism leading to low oral bioavailability. Drug absorption increased with lipid-rich diet when compared with fasted conditions and the absorption profile manifested secondary peaks in some patients. Ezutromid followed a biphasic elimination [170]. Ezutromid was discontinued in 2018 after failing to show any benefit as a modifying disease drug in phase II trial [171].

\section{Conclusions}

Over the past few years, a multiplicity of important functions of AHR has been found, surpassing its original role as a xenobiotic sensor and regulator of xenobiotic detoxification. In fact, AHR has been confirmed as an important signaling molecule regulating and maintaining homeostasis in different cells, tissues, and organs. Novel data highlights AHRCYP1A1 axis activation in the mechanisms of disease, justifying the putative value of its therapeutic blockade. Thus, it is timely to investigate and better characterize the pharmacological properties of blockers of the AHR-CYP1A1 axis. AHR-CYP1A1 blockers might be useful in the treatment of chronic diseases including diabetes, hypertension, skeletal muscle disorders, and cancer, diseases known for being poorly controlled with the currently available drugs. For that, compiling evidence of pre-clinical pilot studies performed so far with AHR-CYP1A1 blockers is needed. Notably, many drugs identified in vitro demonstrated to be auto-inducers of its own metabolism in vivo, and this effect was tissue/ organ specific. Most of the tested compounds ameliorated the disease although some potential adverse reactions might be also anticipated. Summing up, we believe the information herein compiled will be helpful to guide researchers when planning experiments with AHR-CYP1A1 blockers. Finally, and in view of the ongoing clinical studies using three AHR antagonists, we reinforce a call for further evidence on the pharmacological properties of AHR-CYP1A1 blockers.

Author's contribution EM and SAP had the idea for this review; NC, AP, MJC, TR, JM, and SAP contributed to the literature search and critical appraisal of the studies; all authors contributed to the writing and review of the manuscript.

Funding This work was supported by the Fundação para Ciência e Tecnologia [PTDC/MED-TOX/30418/2017] and iNOVA4Health [UID/ Multi/04462/2013]. NRC, MJC, and JM were supported by FCT [PhD grant PD/BD/114257/2016, PhD grant SFRH/BD/131331/2017 and Post-doctoral contract PTDC/MED-TOX/30418/2017, respectively].

\section{Declarations}

Conflict of interest The authors declare no competing interests.

\section{References}

1. Mimura J, Fujii-Kuriyama Y (2003) Functional role of AhR in the expression of toxic effects by TCDD. Biochim Biophys Acta - Gen Subj 1619:263-268. https://doi.org/10.1016/S03044165(02)00485-3

2. Nebert DW (2017) Aryl hydrocarbon receptor (AHR): "pioneer member" of the basic-helix/loop/helix per-Arnt-sim (bHLH/PAS) family of "sensors" of foreign and endogenous signals. Prog Lipid Res 67:38-57. https://doi.org/10.1016/j.plipres.2017.06.001 
3. Denison MS, Soshilov AA, He G, Degroot DE, Zhao B (2011) Exactly the same but different: promiscuity and diversity in the molecular mechanisms of action of the aryl hydrocarbon (dioxin) receptor, toxicol. Sci 124:1-22. https://doi.org/10.1093/toxsci/ kfr218

4. Larigot L, Juricek L, Dairou J, Coumoul X (2018) AhR signaling pathways and regulatory functions. Biochim Open 7:1-9. https:// doi.org/10.1016/j.biopen.2018.05.001

5. Degroot D, He G, Fraccalvieri D, Bonati L, Pandini AA, Denison MS (2011) AHR Ligands: promiscuity in Binding and Diversity in Response, in: AH Recept. Biol. Toxicol., John Wiley and Sons, Hoboken, NJ, USA, pp. 63-79. https://doi.org/10.1002/9781118140574.ch4

6. Yi T, Wang J, Zhu K, Tang Y, Huang S, Shui X, Ding Y, Chen C, Lei W (2018) Aryl Hydrocarbon receptor: a new player of pathogenesis and therapy in cardiovascular diseases. Biomed Res Int 2018. https://doi.org/10.1155/2018/6058784

7. Correia MJ, Pimpão AB, Lopes-Coelho F, Sequeira CO, Coelho NR, Gonçalves-Dias C, Barouki R, Coumoul X, Serpa J, Morello J, Monteiro EC, Pereira SA (2021) Aryl hydrocarbon receptor and cysteine redox dynamics underlie (mal)adaptive mechanisms to chronic intermittent hypoxia in kidney cortex, antioxidants. 10:1484. https://doi.org/10.3390/ANTIOX10091484

8. Nguyen LP, Bradfield CA (2008) The search for endogenous activators of the aryl hydrocarbon receptor. Chem Res Toxicol 21:102-116. https://doi.org/10.1021/tx7001965

9. Hubbard TD, Murray IA, Perdew GH (2015) Indole and tryptophan metabolism: endogenous and dietary routes to ah receptor activation. Drug Metab Dispos 43:1522-1535. https://doi.org/ 10.1124/dmd.115.064246

10. Barouki R, Aggerbeck M, Aggerbeck L, Coumoul X (2012) The aryl hydrocarbon receptor system. Drug Metabol Drug Interact 27:3-8. https://doi.org/10.1515/dmdi-2011-0035

11. Guyot E, Chevallier A, Barouki R, Coumoul X (2013) The AhR twist: ligand-dependent AhR signaling and pharmaco-toxicological implications. Drug Discov Today 18:479-486. https://doi.org/10. 1016/j.drudis.2012.11.014

12. Hu W, Sorrentino C, Denison MS, Kolaja K, Fielden MR (2007) Induction of Cyp1a1 is a nonspecific biomarker of aryl hydrocarbon receptor activation: results of large scale screening of pharmaceuticals and toxicants in vivo and in vitro. Mol Pharmacol 71:1475-1486. https://doi.org/10.1124/mol.106.032748

13. Mimura J, Ema M, Sogawa K, Fujii-Kuriyama Y (1999) Identification of a novel mechanism of regulation of Ah (dioxin) receptor function. Genes Dev 13:20-25. https://doi.org/10.1101/gad.13.1.20

14. Wilson SR, Joshi AD, Elferink CJ (2013) The tumor suppressor Kruppel-like factor 6 is a novel aryl hydrocarbon receptor DNA binding partner. J Pharmacol Exp Ther 345:419-429. https://doi. org/10.1124/jpet.113.203786

15. Oesch-Bartlomowicz B, Huelster A, Wiss $\mathrm{O}$, Antoniou-Lipfert $\mathrm{P}$, Dietrich C, Arand M, Weiss C, Bockamp E, Oesch F (2005) Aryl hydrocarbon receptor activation by cAMP vs. dioxin: divergent signaling pathways. Proc Natl Acad Sci USA 102:9218-9223. https://doi.org/10.1073/pnas.0503488102

16. McMillan BJ, Bradfield CA (2007) The aryl hydrocarbon receptor is activated by modified low-density lipoprotein. Proc Natl Acad Sci U S A 104:1412-1417. https://doi.org/10.1073/pnas.0607296104

17. Han Z, Miwa Y, Obikane H, Mitsumata M, Takahashi-Yanaga F, Morimoto S, Sasaguri T (2008) Aryl hydrocarbon receptor mediates laminar fluid shear stress-induced CYP1A1 activation and cell cycle arrest in vascular endothelial cells. Cardiovasc Res 77:809-818. https://doi.org/10.1093/cvr/cvm095

18. Xiao W, Son J, Vorrink SU, Domann FE, Goswami PC (2015) Ligand-independent activation of aryl hydrocarbon receptor signaling in PCB3-quinone treated $\mathrm{HaCaT}$ human keratinocytes. Toxicol Lett 233:258-266. https://doi.org/10.1016/j.toxlet.2015. 02.005
19. Lee AJ, Cai MX, Thomas PE, Conney AH, Zhu BT (2003) Characterization of the oxidative metabolites of $17 \beta$-estradiol and estrone formed by 15 selectively expressed human cytochrome P450 isoforms. Endocrinology 144:3382-3398. https://doi.org/ 10.1210/en.2003-0192

20. Schwarz D, Kisselev P, Ericksen SS, Szklarz GD, Chernogolov A, Honeck H, Schunck WH, Roots I (2004) Arachidonic and eicosapentaenoic acid metabolism by human CYP1A1: highly stereoselective formation of 17(R),18(S)-epoxyeicosatetraenoic acid. Biochem Pharmacol 67:1445-1457. https://doi.org/10. 1016/j.bcp.2003.12.023

21. Ma X, Idle JR, Krausz KW, Gonzalez FJ (2005) Metabolism of melatonin by human cytochromes P450. Drug Metab Dispos 33:489-494. https://doi.org/10.1124/dmd.104.002410

22. Favreau LV, Pickett CB (1991) Transcriptional regulation of the rat $\mathrm{NAD}(\mathrm{P}) \mathrm{H}$ :quinone reductase gene. Identification of regulatory elements controlling basal level expression and inducible expression by planar aromatic compounds and phenolic antioxidants. J Biol Chem 266:4556-4561. http://www.jbc.org/ (accessed June 15, 2020)

23. Watson AJ, Hankinson O (1992) Dioxin-and Ah Receptor-dependent protein binding to xenobiotic responsive elements and G-rich DNA studied by in vivo footprinting. J Biol Chem 266:6874-6878

24. Baba T, Mimura J, Gradin K, Kuroiwa A, Watanabe T, Matsuda Y, Inazawa J, Sogawa K, Fujii-Kuriyama Y (2001) Structure and expression of the ah receptor repressor gene. J Biol Chem 276:33101-33110. https://doi.org/10.1074/jbc.M011497200

25. Wang X, Hawkins BT, Miller DS (2011) Aryl hydrocarbon receptor-mediated up-regulation of ATP-driven xenobiotic efflux transporters at the blood-brain barrier. FASEB J 25:644. https:// doi.org/10.1096/FJ.10-169227

26. Davarinos NA, Pollenz RS (1999) Aryl hydrocarbon receptor imported into the nucleus following ligand binding is rapidly degraded via the cytosplasmic proteasome following nuclear export. J Biol Chem 274:28708-28715. https://doi.org/10.1074/ jbc.274.40.28708

27. Akahoshi E, Yoshimura S, Uruno S, Ishihara-Sugano M (2009) Effect of dioxins on regulation of tyrosine hydroxylase gene expression by aryl hydrocarbon receptor: a neurotoxicology study. Environ Heal A Glob Access Sci Source 8:24. https://doi. org/10.1186/1476-069X-8-24

28. Matikainen T, Perez GI, Jurisicova A, Pru JK, Schlezinger JJ, Ryu HY, Laine J, Sakai T, Korsmeyer SJ, Casper RF, Sherr DH, Tilly JL (2001) Aromatic hydrocarbon receptor-driven Bax gene expression is required for premature ovarian failure caused by biohazardous environmental chemicals. Nat Genet 28:355-360. https://doi.org/10.1038/ng575

29. Boutros PC, Moffat ID, Franc MA, Tijet N, Tuomisto J, Pohjanvirta R, Okey AB (2004) Dioxin-responsive AHRE-II gene battery: identification by phylogenetic footprinting. Biochem Biophys Res Commun 321:707-715. https://doi.org/10.1016/j.bbrc.2004.06.177

30. Coelho NR, Tomkiewicz C, Correia MJ, Gonçalves-Dias C, Barouki R, Pereira SA, Coumoul X, Monteiro EC (2020) First evidence of aryl hydrocarbon receptor as a druggable target in hypertension induced by chronic intermittent hypoxia. Pharmacol Res 159:104869. https://doi.org/10.1016/j.phrs.2020.104869

31. Coelho NR, Matos C, Pimpão AB, Correia MJ, Sequeira CO, Morello J, Pereira SA, Monteiro EC (2021) AHR canonical pathway: in vivo findings to support novel antihypertensive strategies. Pharmacol Res 105407. https://doi.org/10.1016/j.phrs.2020.105407

32. Bersten DC, Sullivan AE, Peet DJ, Whitelaw ML (2013) BHLHPAS proteins in cancer. Nat Rev Cancer 13:827-841. https://doi. org/10.1038/nrc3621

33. Zhao B, Degroot DE, Hayashi A, He G, Denison MS (2010) CH223191 Is a ligand-selective antagonist of the Ah (dioxin) receptor. Toxicol Sci 117:393-403. https://doi.org/10.1093/toxsci/kfq217 
34. Nazarenko DA, Dertinger SD, Gasiewicz TA (2001) In vivo antagonism of AhR-mediated gene induction by 3-methoxy-4-nitroflavone in TCDD-responsive lacZ mice. Toxicol Sci 61:256-264. https:// doi.org/10.1093/toxsci/61.2.256

35. Datta A, Bhasin N, Kim H, Ranjan M, Rider B, Abd Elmageed ZY, Mondal D, Agrawal KC, Abdel-Mageed AB (2015) Selective targeting of FAK-Pyk2 axis by alpha-naphthoflavone abrogates doxorubicin resistance in breast cancer cells. Cancer Lett 362:25-35. https://doi.org/10.1016/j.canlet.2015.03.009

36. Timme-Laragy AR, Cockman CJ, Matson CW, Di Giulio RT (2007) Synergistic induction of AHR regulated genes in developmental toxicity from co-exposure to two model PAHs in zebrafish. Aquat Toxicol 85:241-250. https://doi.org/10.1016/j. aquatox.2007.09.005

37. Gouédard C, Barouki R, Morel Y (2004) Induction of the paraoxonase-1 gene expression by resveratrol, arterioscler. Thromb Vasc Biol 24:2378-2383. https://doi.org/10.1161/01. ATV.0000146530.24736.ce

38. Stejskalova L, Pavek P (2011) The function of cytochrome P450 1A1 enzyme (CYP1A1) and aryl hydrocarbon receptor (AhR) in the placenta. Curr Pharm Biotechnol 12:715-730. https://doi. org/10.2174/138920111795470994

39. Mescher M, Haarmann-Stemmann T (2018) Modulation of CYP1A1 metabolism: from adverse health effects to chemoprevention and therapeutic options. Pharmacol Ther 187:71-87. https://doi.org/10.1016/j.pharmthera.2018.02.012

40. Schlezinger JJ, White RD, Stegeman JJ (1999) Oxidative inactivation of cytochrome P-450 1A (CYP1A) stimulated by 3,3',4,4'-tetrachlorobiphenyl: production of reactive oxygen by vertebrate CYP1As. Mol Pharmacol 56:588-597. https://doi.org/ 10.1124/mol.56.3.588

41. Beresford AP (1993) CYP1A1: Friend or foe? Drug Metab Rev 25:503-517. https://doi.org/10.3109/03602539308993984

42. Eugster HP, Probst M, Würgler FE, Sengstag C (1993) Caffeine, estradiol, and progesterone interact with human CYP1A1 and CYP1A2. Evidence from cDNA-directed expression in Saccharomyces cerevisiae. Drug Metab Dispos 21:43LP-49. http://dmd. aspetjournals.org/content/21/1/43.abstract

43. Stiborová M, Martínek V, Rýdlová H, Koblas T, Hodek P (2005) Expression of cytochrome P450 1A1 and its contribution to oxidation of a potential human carcinogen 1-phenylazo-2-naphthol (Sudan I) in human livers. Cancer Lett 220:145-154. https://doi. org/10.1016/j.canlet.2004.07.036

44. Badal S, Delgoda R (2014) Role of the modulation of CYP1A1 expression and activity in chemoprevention. J Appl Toxicol 34:743-753. https://doi.org/10.1002/jat.2968

45. Go RE, Hwang KA, Choi KC (2015) Cytochrome P450 1 family and cancers. J Steroid Biochem Mol Biol 147:24-30. https://doi. org/10.1016/j.jsbmb.2014.11.003

46. Ma Q, Lu AYH (2007) CYP1A induction and human risk assessment: An evolving tale of in vitro and in vivo studies. Drug Metab Dispos 35:1009-1016. https://doi.org/10.1124/dmd.107. 015826

47. Joshi P, McCann GJP, Sonawane VR, Vishwakarma RA, Chaudhuri B, Bharate SB (2017) Identification of potent and selective CYP1A1 inhibitors via combined ligand and structure-based virtual screening and their in vitro validation in sacchrosomes and live human cells. J Chem Inf Model 57:1309-1320. https://doi.org/10.1021/acs.jcim. $7 b 00095$

48. Marinho AT, Dias CG, Pinheiro PF, Lemos AR, Antunes AMM, Marques MM, Monteiro EC, Miranda JP, Pereira SA (2016) Nevirapine modulation of paraoxonase-1 in the liver: an in vitro three-model approach. Eur J Pharm Sci 82:147-153. https://doi. org/10.1016/J.EJPS.2015.11.019

49. Pinheiro PF, Pereira SA, Harjivan SG, Martins IL, Marinho AT, Cipriano M, Jacob CC, Oliveira NG, Castro MF, Marques MM,
Antunes AMM, Miranda JP (2016) Hepatocyte spheroids as a competent in vitro system for drug biotransformation studies: nevirapine as a bioactivation case study. Arch Toxicol 91:11991211. https://doi.org/10.1007/s00204-016-1792-x

50. Lu YF, Santostefano M, Cunningham BDM, Threadgill MD, Safe S (1995) Identification of 3'-methoxy-4'-nitroflavone as a pure aryl hydrocarbon $(\mathrm{Ah})$ receptor antagonist and evidence for more than one form of the nuclear Ah receptor in MCF-7 human breast cancer cells. Arch Biochem Biophys 316:470-477. https://doi. org/10.1006/abbi.1995.1062

51. Dertinger SD, Lantum HBM, Silverstone AE, Gasiewicz TA (2000) Effect of 3'-methoxy-4'-nitroflavone on benzo[a]pyrene toxicity. Aryl hydrocarbon receptor-dependent and -independent mechanisms. Biochem Pharmacol 60:189-196. https://doi.org/ 10.1016/S0006-2952(00)00314-2

52. Dertinger SD, Nazarenko DA, Silverstone AE, Gasiewicz TA (2001) Aryl hydrocarbon receptor signaling plays a significant role in mediating benzo[a]pyrene-and cigarette smoke condensate-induced cytogenetic damage in vivo. Carcinogenesis 22:171-177. https://doi.org/10.1093/carcin/22.1.171

53. Navid F, Bruhs A, Schuller W, Fritsche E, Krutmann J, Schwarz T, Schwarz A (2013) The aryl hydrocarbon receptor is involved in UVR-Induced immunosuppression. J Invest Dermatol 133:2763-2770. https://doi.org/10.1038/jid.2013.221

54. Campbell DR, Kurzer MS (1993) Flavonoid inhibition of aromatase enzyme activity in human preadipocytes. J Steroid Biochem Mol Biol 46:381-388. https://doi.org/10.1016/09600760(93)90228-O

55. Shimada T, Yamazaki H, Foroozesh M, Hopkins NE, Alworth WL, Guengerich FP (1998) Selectivity of polycyclic inhibitors for human cytochrome P450s 1A1, 1A2, and 1B1. Chem Res Toxicol 11:1048-1056. https://doi.org/10.1021/tx980090+

56. Walsh AA, Szklarz GD, Scott EE (2013) Human cytochrome P450 1A1 structure and utility in understanding drug and xenobiotic metabolism. J Biol Chem 288:12932-12943. https://doi. org/10.1074/jbc.M113.452953

57. Sansen S, Yano JK, Reynald RL, Schoch GA, Griffin KJ, Stout CD, Johnson EF (2007) Adaptations for the oxidation of polycyclic aromatic hydrocarbons exhibited by the structure of human P450 1A2. J Biol Chem 282:14348-14355. https://doi.org/10. 1074/jbc.M611692200

58. Wang A, Savas U, Stout CD, Johnson EF (2011) Structural characterization of the complex between $\alpha$-naphthoflavone and human cytochrome P450 1B1. J Biol Chem 286:5736-5743. https://doi.org/10.1074/jbc.M110.204420

59. Sineva EV, Rumfeldt JAO, Halpert JR, Davydov DR (2013) A large-scale allosteric transition in cytochrome P450 3A4 revealed by luminescence resonance energy transfer (LRET). PLoS One 8. https://doi.org/10.1371/journal.pone.0083898

60. Thompson KE, Bourguet SM, Christian PJ, Benedict JC, Sipes IG, Flaws JA, Hoyer PB (2005) Differences between rats and mice in the involvement of the aryl hydrocarbon receptor in 4-vinylcyclohexene diepoxide-induced ovarian follicle loss. Toxicol Appl Pharmacol 203:114-123. https://doi.org/10.1016/j.taap.2004.07.010

61. Jang JY, Shin S, il Choi B, Park D, Jeon JH, Hwang SY, Kim JC, Kim YB, Nahm SS (2007) Antiteratogenic effects of $\alpha$-naphthoflavone on 2,3,7,8-tetrachlorodibenzo-p-dioxin (TCDD) exposed mice in utero. Reprod Toxicol 24:303-309. https://doi.org/10.1016/j.reprotox.2007.08.002

62. Moyer BJ, Rojas IY, Kerley-Hamilton JS, Hazlett HF, Nemani KV, Trask HW, West RJ, Lupien LE, Collins AJ, Ringelberg CS, Gimi B, Kinlaw WB, Tomlinson CR (2016) Inhibition of the aryl hydrocarbon receptor prevents Western diet-induced obesity. Model for AHR activation by kynurenine via oxidized-LDL, TLR2/4, TGF $\beta$, and IDO1. Toxicol Appl Pharmacol 300:13-24. https://doi.org/10.1016/j.taap.2016.03.011 
63. Moyer BJ, Rojas IY, Kerley-Hamilton JS, Nemani KV, Trask HW, Ringelberg CS, Gimi B, Demidenko E, Tomlinson CR (2017) Obesity and fatty liver are prevented by inhibition of the aryl hydrocarbon receptor in both female and male mice. Nutr Res 44:38-50. https://doi.org/10.1016/j.nutres.2017.06.002

64. Xia H, Zhu X, Zhang X, Jiang H, Li B, Wang Z, Li D, Jin Y (2019) Alpha-naphthoflavone attenuates non-alcoholic fatty liver disease in oleic acid-treated HepG2 hepatocytes and in high fat diet-fed mice. Biomed Pharmacother 118:109287. https://doi.org/ 10.1016/j.biopha.2019.109287

65. Kyoreva M, Li Y, Hoosenally M, Hardman-Smart J, Morrison K, Tosi I, Tolaini M, Barinaga G, Stockinger B, Mrowietz U, Nestle FO, Smith CH, Barker JN, Di Meglio P (2021) CYP1A1 Enzymatic activity influences skin inflammation via regulation of the AHR pathway. J Invest Dermatol 141:1563. https://doi.org/ 10.1016/J.JID.2020.11.024

66. Parks AJ, Pollastri MP, Hahn ME, Stanford EA, Novikov O, Franks DG, Haigh SE, Narasimhan S, Ashton TD, Hopper TG, Kozakov D, Beglov D, Vajda S, Schlezinger JJ, Sherr DH (2014) In silico identification of an aryl hydrocarbon receptor antagonist with biological activity in vitro and in vivo. Mol Pharmacol 86:593-608. https://doi.org/10.1124/mol.114.093369

67. Aguiniga LM, Searl TJ, Rahman-Enyart A, Yaggie RE, Yang W, Schaeffer AJ, Klumpp DJ (2019) Acyloxyacyl hydrolase regulates voiding activity. Am J Physiol 317:289-300. https://doi.org/ 10.1152/AJPRENAL.00442.2019

68. Kim SH, Henry EC, Kim DK, Kim YH, Kum JS, Myoung SH, Lee TG, Kang JK, Gasiewicz TA, Sung HR, Suh PG (2006) Novel compound 2-methyl-2H-pyrazole-3-carboxylic acid (2-methyl-4-o- tolylazo-phenyl)-amide ( $\mathrm{CH}-223191)$ prevents 2,3,7,8-TCDD-induced toxicity by antagonizing the aryl hydrocarbon receptor. Mol Pharmacol 69:1871-1878. https://doi.org/ 10.1124/mol.105.021832

69. Choi EY, Lee H, Dingle RWC, Kim KB, Swanson HI (2012) Development of novel CH223191-based antagonists of the aryl hydrocarbon receptor. Mol Pharmacol 81:3-11. https://doi.org/ 10.1124/mol.111.073643

70. Monteleone I, Zorzi F, Marafini I, Di Fusco D, Dinallo V, Caruso R, Izzo R, Franzè E, Colantoni A, Pallone F, Monteleone G (2016) Aryl hydrocarbon receptor-driven signals inhibit collagen synthesis in the gut. Eur J Immunol 46:1047-1057. https://doi. org/10.1002/eji.201445228

71. Liu C, Li Y, Chen Y, Huang S, Wang X, Luo S, Su Y, Zhou L, Luo X (2020) Baicalein Restores the Balance of Th17/Treg cells via aryl hydrocarbon receptor to attenuate colitis. Mediators Inflamm. https://doi.org/10.1155/2020/5918587

72. Cuartero MI, Ballesteros I, De La Parra J, Harkin AL, AbautretDaly A, Sherwin E, Fernández-Salguero P, Corbí ÁL, Lizasoain I, Moro MA (2014) L-kynurenine/aryl hydrocarbon receptor pathway mediates brain damage after experimental stroke. Circulation 130:2040-2051. https://doi.org/10.1161/ CIRCULATIONAHA.114.011394

73. Tanaka M, Fujikawa M, Oguro A, Itoh K, Vogel CFA, Ishihara Y (2021) Involvement of the microglial aryl hydrocarbon receptor in neuroinflammation and vasogenic edema after ischemic stroke. Cells 10:718. https://doi.org/10.3390/CELLS10040718

74. Dean A, Gregorc T, Docherty CK, Harvey KY, Nilsen M, Morrell NW, MacLean MR (2017) Role of the aryl hydrocarbon receptor in sugen 5416-induced experimental pulmonary hypertension. Am J Respir Cell Mol Biol 58:320-330. https://doi.org/10.1165/ remb.2017-0260OC

75. Löfroth G, Rannug A (1988) Ah receptor ligands in tobacco smoke. Toxicol Lett 42:131-136. https://doi.org/10.1016/03784274(88)90070-7

76. Rico de Souza A, Traboulsi H, Wang X, Fritz JH, Eidelman DH, Baglole CJ (2021) The aryl hydrocarbon receptor attenuates acute cigarette smoke-induced airway neutrophilia independent of the dioxin response element. Front Immunol 0:274. https:// doi.org/10.3389/FIMMU.2021.630427

77. Jia Y, Tao Y, Lv C, Xia Y, Wei Z, Dai Y (2019) Tetrandrine enhances the ubiquitination and degradation of Syk through an AhR-c-src-c-Cbl pathway and consequently inhibits osteoclastogenesis and bone destruction in arthritis. Cell Death Dis 10. https://doi.org/10.1038/s41419-018-1286-2

78. Pierre S, Chevallier A, Teixeira-Clerc F, Ambolet-Camoit A, Bui L-C, Bats A-S, Fournet J-C, Fernandez-Salguero P, Aggerbeck M, Lotersztajn S, Barouki R, Coumoul X (2014) Aryl hydrocarbon receptor-dependent induction of liver fibrosis by dioxin. Toxicol Sci 137:114-124. https://doi.org/10.1093/TOXSCI/KFT236

79. Fernandez-Salguero PM, Ward JM, Sundberg JP, Gonzalez FJ (1997) Lesions of aryl-hydrocarbon receptor-deficient mice. Vet Pathol 34:605-614. https://doi.org/10.1177/030098589703400609

80. Shi Y, Tang B, Yu J, Luo Y, Xiao Y, Pi Z, Tang R, Wang Y, Kanekura T, Zeng Z, Xiao R (2020) Aryl hydrocarbon receptor signaling activation in systemic sclerosis attenuates collagen production and is a potential antifibrotic target. Int Immunopharmacol 88:106886. https://doi.org/10.1016/J.INTIMP.2020.106886

81. Yang S, Tan L, Chen Y, Liu A, Hong M, Peng Z (2020) DIM mitigates the development of experimental autoimmune encephalomyelitis by maintaining the stability and suppressive function of regulatory T cells. Cell Immunol 358:104238. https://doi.org/ 10.1016/J.CELLIMM.2020.104238

82. Mohammadi H, Daryabor G, Bahraman AG, Keshavarzi M, Kalantar K, Mohammadi-Bardbori A (2021) Aryl hydrocarbon receptor engagement during redox alteration determines the fate of CD4+ T cells in C57BL/6 mice. J Biochem Mol Toxicol 35:e22821. https://doi.org/10.1002/JBT.22821

83. Kunitomi C, Harada M, Kusamoto A, Azhary JM, Nose E, Koike H, Xu Z, Urata Y, Takahashi N, Wada-Hiraike O, Hirota Y, Koga K, Fujii T, Osuga Y (2021) Induction of aryl hydrocarbon receptor in granulosa cells by endoplasmic reticulum stress contributes to pathology of polycystic ovary syndrome. Mol Hum Reprod 27. https://doi.org/10.1093/MOLEHR/GAAB003

84. Abuin-Martínez C, Vidal R, Gutiérrez-López MD, Pérez-Hernández M, Giménez-Gómez P, Morales-Puerto N, O’Shea E, Colado MI (2021) Increased kynurenine concentration attenuates serotonergic neurotoxicity induced by 3,4-methylenedioxymethamphetamine (MDMA) in rats through activation of aryl hydrocarbon receptor. Neuropharmacology 187:108490. https://doi.org/10.1016/J.NEUROPHARM.2021. 108490

85. de Castro LF, Ferreira MC, da Silva RM, de Blotta MHSL, L.N.A. Longhi, Mamoni RL (2013) Characterization of the immune response in human paracoccidioidomycosis. J Infect 67:470-485. https://doi.org/10.1016/J.JINF.2013.07.019

86. Quintana FJ, Basso AS, Iglesias AH, Korn T, Farez MF, Bettelli E, Caccamo M, Oukka M, Weiner HL (2008) Control of Treg and TH17 cell differentiation by the aryl hydrocarbon receptor. Nature 453:65-71. https://doi.org/10.1038/nature06880

87. de Araújo EF, Preite NW, Veldhoen M, Loures FV, Calich VLG (2020) Pulmonary paracoccidioidomycosis in AhR deficient hosts is severe and associated with defective Treg and Th22 responses. Sci Rep 10:1-16. https://doi.org/10.1038/ s41598-020-68322-6

88. de Araújo EF, Loures FV, Preite NW, Feriotti C, AL Galdino N, Costa TA, Calich VLG (2021) AhR Ligands modulate the differentiation of innate lymphoid cells and $t$ helper cell subsets that control the severity of a pulmonary fungal infection. Front Immunol 1277. https://doi.org/10.3389/FIMMU.2021.630938

89. Giovannoni F, Bosch I, Polonio CM, Torti MF, Wheeler MA, Li Z, Romorini L, Rodriguez Varela MS, Rothhammer V, Barroso A, Tjon EC, Sanmarco LM, Takenaka MC, Modaresi SMS, Gutiérrez-Vázquez C, Zanluqui NG, dos Santos NB, 
Munhoz CD, Wang Z, Damonte EB, Sherr D, Gehrke L, Peron JPS, Garcia CC, Quintana FJ (2020) AHR is a Zika virus host factor and a candidate target for antiviral therapy. Nat Neurosci 23:939-951. https://doi.org/10.1038/s41593-020-0664-0

90. Liu Y, Lv J, Liu J, Li M, Xie J, Lv Q, Deng W, Zhou N, Zhou Y, Song J, Wang P, Qin C, Tong W-M, Huang B (2020) Mucus production stimulated by IFN-AhR signaling triggers hypoxia of COVID-19. Cell Res 30:1078-1087. https://doi.org/10.1038/ s41422-020-00435-z

91. Smith KJ, Murray IA, Tanos R, Tellew J, Boitano AE, Bisson WH, Kolluri SK, Cooke MP, Perdew GH (2011) Identification of a high-affinity ligand that exhibits complete aryl hydrocarbon receptor antagonism. J Pharmacol Exp Ther 338:318-327. https://doi.org/10.1124/jpet.110.178392

92. Fang Z-Z, Krausz KW, Nagaoka K, Tanaka N, Gowda K, Amin SG, Perdew GH, Gonzalez FJ (2014) In vivo effects of the pure aryl hydrocarbon receptor antagonist GNF-351 after oral administration are limited to the gastrointestinal tract. Br J Pharmacol 171:1735-1746. https://doi.org/10.1111/bph.12576

93. Bonnefont-Rousselot D (2016) Resveratrol and cardiovascular diseases. Nutrients 8. https://doi.org/10.3390/nu8050250

94. Harikumar KB, Aggarwal BB (2008) Resveratrol: a multitargeted agent for age-associated chronic diseases. Cell Cycle 7:10201035. https://doi.org/10.4161/cc.7.8.5740

95. Marti N, Bouchoucha N, Sauter KS, Flück CE (2017) Resveratrol inhibits androgen production of human adrenocortical H295R cells by lowering CYP17 and CYP21 expression and activities. PLoS One 12. https://doi.org/10.1371/journal.pone.0174224

96. Beedanagari SR, Bebenek I, Bui P, Hankinson O (2009) Resveratrol inhibits dioxin-induced expression of human CYP1A1 and CYP1B1 by inhibiting recruitment of the aryl hydrocarbon receptor complex and RNA polymerase II to the regulatory regions of the corresponding genes. Toxicol Sci 110:61-67. https://doi.org/ 10.1093/toxsci/kfp079

97. Revel A, Raanani H, Younglai E, Xu J, Rogers I, Han R, Savouret JF, Casper RF (2003) Resveratrol, a natural aryl hydrocarbon receptor antagonist, protects lung from DNA damage and apoptosis caused by benzo[a]pyrene. J Appl Toxicol 23:255-261. https://doi.org/10.1002/jat.916

98. Singh NP, Singh US, Nagarkatti M, Nagarkatti PS (2011) Resveratrol (3,5,4'-trihydroxystilbene) protects pregnant mother and fetus from the immunotoxic effects of 2,3,7,8-tetrachlorodibenzop-dioxin. Mol Nutr Food Res 55:209-219. https://doi.org/10. 1002/mnfr.201000206

99. Revel A, Raanani H, Younglai E, Xu J, Han R, Savouret JF, Casper RF (2001) Resveratrol, a natural aryl hydrocarbon receptor antagonist, protects sperm from DNA damage and apoptosis caused by benzo(a)pyrene. Reprod Toxicol 15:479-486. https:// doi.org/10.1016/S0890-6238(01)00149-6

100. Banerjee B, Nandi P, Chakraborty S, Raha S, Sen PC, Jana K (2016) Resveratrol ameliorates benzo(a)pyrene-induced testicular dysfunction and apoptosis: Involvement of p38 MAPK/ATF2/ iNOS signaling. J Nutr Biochem 34:17-29. https://doi.org/10. 1016/j.jnutbio.2016.04.003

101. Banerjee B, Chakraborty S, Ghosh D, Raha S, Sen PC (2016) Jana K, Benzo(a)pyrene induced p53 mediated male germ cell apoptosis: synergistic protective effects of curcumin and resveratrol. Front Pharmacol 7. https://doi.org/10.3389/ fphar.2016.00245

102. Erthal RP, Siervo GEML, Silveira LTR, Scarano WR, Fernandes GSA (2018) Can resveratrol attenuate testicular damage in neonatal and adult rats exposed to 2,3,7,8-tetrachlorodibenzo-pdioxin during gestation? Reprod Fertil Dev 30:442-450. https:// doi.org/10.1071/RD17180

103. Silveira LTR, de Mello Santos T, Camora LF, Pinho CF, Anselmo-Franci JA, Domeniconi RF, Justulin LA, Barbisan LF,
Scarano WR (2018) Protective effect of resveratrol on urogenital sinus and prostate development in rats exposed in utero to TCDD (2,3,7,8-tetrachlorodibenzo-p-dioxin). Reprod Toxicol 83:82-92. https://doi.org/10.1016/j.reprotox.2018.06.012

104. Ghosh J, Chowdhury AR, Srinivasan S, Chattopadhyay M, Bose M, Bhattacharya S, Raza H, Fuchs SY, Rustgi AK, Gonzalez FJ, Avadhani NG (2018) Cigarette smoke toxins-induced mitochondrial dysfunction and pancreatitis involves aryl hydrocarbon receptor mediated Cyp1 gene expression: protective effects of resveratrol. Toxicol Sci 166:428-440. https://doi.org/10.1093/ toxsci/kfy206

105. eun Lee J, Cho SG, Ko SG, Ahrmad SA, Puga A, Kim K (2020) Regulation of a long noncoding RNA MALAT1 by aryl hydrocarbon receptor in pancreatic cancer cells and tissues. Biochem Biophys Res Commun 532:563-569. https://doi.org/ 10.1016/J.BBRC.2020.08.053

106. Mokhtar MM, Khidr EG, Shaban HM, Allam S, Elsadek BEM, Salama SA, Ali SS (2020) The effect of aryl hydrocarbon receptor ligands on gentamicin-induced nephrotoxicity in rats. Environ Sci Pollut Res 27:16189-16202. https://doi.org/10.1007/ s11356-020-08073-Z

107. Amaya SC, Savaris RF, Filipovic CJ, Wise JD, Hestermann E, Young SL, Lessey BA (2014) Resveratrol and endometrium: a closer look at an active ingredient of red wine using in vivo and in vitro models. Reprod Sci 21:1362-1369. https://doi.org/10. $1177 / 1933719114525271$

108. Papoutsis AJ, Selmin OI, Borg JL, Romagnolo DF (2015) Gestational exposure to the AhR agonist 2,3,7,8-tetrachlorodibenzo-pdioxin induces BRCA-1 promoter hypermethylation and reduces BRCA-1 expression in mammary tissue of rat offspring: Preventive effects of resveratrol. Mol Carcinog 54:261-269. https://doi. org/10.1002/mc.22095

109. Wang K, Feng C, Li C, Yao J, Xie X, Gong L, Luan Y, Xing G, Zhu X, Qi X, Ren J (2015) Baicalin protects mice from aristolochic acid I-induced kidney injury by induction of CYP1A through the aromatic hydrocarbon receptor. Int J Mol Sci 16:16454-16468. https://doi.org/10.3390/ijms160716454

110. Anandasadagopan SK, Singh NM, Raza H, Bansal S, Selvaraj V, Singh S, Chowdhury AR, Leu NA, Avadhani NG (2017) $\beta$-naphthoflavoneinduced mitochondrial respiratory damage in Cyp1 knockout mouse and in cell culture systems: attenuation by resveratrol treatment. Oxid Med Cell Longev 2017. https://doi.org/10.1155/2017/5213186

111. Zhou Y, Jiang R, An L, Wang H, Cheng S, Qiong S, Weng Y (2017) Benzo[a]pyrene impedes self-renewal and differentiation of mesenchymal stem cells and influences fracture healing. Sci Total Environ 587-588:305-315. https://doi.org/10.1016/j. scitotenv.2017.02.152

112. Liu W-C, Shyu J-F, Lin Y-F, Chiu H-W, Lim PS, Lu C-L, Zhen C-M, Hou Y-C, Chen P-H, Lu K-C (2020) Resveratrol rescue indoxyl sulfate-induced deterioration of osteoblastogenesis via the aryl hydrocarbon receptor /MAPK pathway. Int J Mol Sci 21:7483. https://doi.org/10.3390/IJMS21207483

113. Wenzel E, Somoza V (2005) Metabolism and bioavailability of trans-resveratrol. Mol Nutr Food Res 49:472-481. https://doi. org/10.1002/mnfr.200500010

114. Kapetanovic IM, Muzzio M, Huang Z, Thompson TN, McCormick DL (2010) Pharmacokinetics, oral bioavailability, and metabolic profile of resveratrol and its dimethylether analog, pterostilbene, in rats. Cancer Chemother Pharmacol 68:593-601. https://doi.org/ 10.1007/s00280-010-1525-4

115. Baker NA, Karounos M, English V, Fang J, Wei Y, Stromberg A, Sunkara M, Morris AJ, Swanson HI, Cassis LA (2013) Coplanar polychlorinated biphenyls impair glucose homeostasis in lean C57BL/6 mice and mitigate beneficial effects of weight loss on glucose homeostasis in obese mice. Environ Health Perspect 121:105-110. https://doi.org/10.1289/ehp.1205421 
116. Baker NA, English V, Sunkara M, Morris AJ, Pearson KJ, Cassis LA (2013) Resveratrol protects against polychlorinated biphenyl-mediated impairment of glucose homeostasis in adipocytes. J Nutr Biochem 24:2168-2174. https://doi.org/10.1016/j.jnutbio.2013.08.009

117. Hsu CN, Lin YJ, Lu PC, Tain YL (2018) Maternal resveratrol therapy protects male rat offspring against programmed hypertension induced by TCDD and dexamethasone exposures: Is it relevant to aryl hydrocarbon receptor? Int J Mol Sci 19:2459. https://doi.org/10.3390/ijms19082459

118. Wang B, Sun J, Li X, Zhou Q, Bai J, Shi Y, Le G (2013) Resveratrol prevents suppression of regulatory T-cell production, oxidative stress, and inflammation of mice prone or resistant to high-fat diet-induced obesity. Nutr Res 33:971-981. https://doi. org/10.1016/j.nutres.2013.07.016

119. Hsu CN, Lin YJ, Tain YL (2019) Maternal exposure to bisphenol a combined with high-fat diet-induced programmed hypertension in adult male rat offspring: effects of resveratrol. Int J Mol Sci 20:4382. https://doi.org/10.3390/ijms20184382

120. Murray IA, Flaveny CA, DiNatale BC, Chairo CR, Schroeder JC, Kusnadi A, Perdew GH (2010) Antagonism of aryl hydrocarbon receptor signaling by $6,2^{\prime}, 4^{\prime}$ - trimethoxyflavone. J Pharmacol Exp Ther 332:135-144. https://doi.org/10.1124/jpet.109.158261

121. Chen WC, Chang LH, Huang SS, Huang YJ, Chih CL, Kuo HC, Lee YH, Lee IH (2019) Aryl hydrocarbon receptor modulates stroke-induced astrogliosis and neurogenesis in the adult mouse brain. J Neuroinflammation 16:187. https://doi.org/10.1186/ s12974-019-1572-7

122. Kwon J-I, Heo H, Ham SJ, Chae YJ, Lee D-W, Kim ST, Min J, Sung YS, Kim KW, Choi Y, Woo DC, Woo C-W (2020) Aryl hydrocarbon receptor antagonism before reperfusion attenuates cerebral ischaemia/reperfusion injury in rats. Sci Rep 10:14906. https://doi.org/10.1038/s41598-020-72023-5

123. Miao H, Cao G, Wu X-Q, Chen Y-Y, Chen D-Q, Chen L, Vaziri ND, Feng Y-L, Su W, Gao Y, Zhuang S, Yu X-Y, Zhang L, Guo Y, Zhao Y-Y (2020) Identification of endogenous 1-aminopyrene as a novel mediator of progressive chronic kidney disease via aryl hydrocarbon receptor activation. Br J Pharmacol 177:3415-3435. https://doi.org/10.1111/BPH.15062

124. Bianchi-Smiraglia A, Bagati A, Fink EE, Affronti HC, Lipchick BC, Moparthy S, Long MD, Rosario SR, Lightman SM, Moparthy K, Wolff DW, Yun DH, Han Z, Polechetti A, Roll MV, Gitlin II, Leonova KI, Rowsam AM, Kandel ES, Gudkov AV, Bergsagel PL, Lee KP, Smiraglia DJ, Nikiforov MA (2018) Inhibition of the aryl hydrocarbon receptor/polyamine biosynthesis axis suppresses multiple myeloma. J Clin Invest 128:4682-4696. https://doi.org/ 10.1172/JCI70712

125. Campesato LF, Budhu S, Tchaicha J, Weng C-H, Gigoux M, Cohen IJ, Redmond D, Mangarin L, Pourpe S, Liu C, Zappasodi R, Zamarin D, Cavanaugh J, Castro AC, Manfredi MG, McGovern K, Merghoub T, Wolchok JD (2020) Blockade of the AHR restricts a Treg-macrophage suppressive axis induced by L-Kynurenine. Nat Commun 11:1-11. https://doi.org/10.1038/s41467-020-17750-z

126. Takahashi E, Fujita KI, Kamataki T, Arimoto-Kobayashi S, Okamoto K, Negishi T (2002) Inhibition of human cytochrome P450 1B1, 1A1 and 1A2 by antigenotoxic compounds, purpurin and alizarin. Mutat Res - Fundam Mol Mech Mutagen 508:147-156. https://doi.org/10.1016/S0027-5107(02) 00212-9

127. Zhang J, Shen X (1997) Antioxidant activities of baicalin, green tea polyphenols and alizarin in vitro and in vivo. J Nutr Environ Med 7:79-90. https://doi.org/10.1080/13590849762664

128. Takahashi E, Arimoto S, Okamoto K, Negishi T (2007) Enhancement of phase II enzyme activity by purpurin resulting in the suppression of MeIQx-DNA-adduct formation in mice. Mutat Res - Genet Toxicol Environ Mutagen 626:128-134. https://doi. org/10.1016/j.mrgentox.2006.09.011
129. Xu L, Xing M, Xu X, Saadeldeen FS, Liu Z, Wei J, Kang W (2019) Alizarin increase glucose uptake through PI3K/Akt signaling and improve alloxan-induced diabetic mice, Future. Med Chem 11:395-406. https://doi.org/10.4155/fmc-2018-0515

130. Stiborová M, Bieler CA, Wiessler M, Frei E (2001) The anticancer agent ellipticine on activation by cytochrome $\mathrm{P} 450$ forms covalent DNA adducts. Biochem Pharmacol 62:1675-1684. https://doi.org/10.1016/S0006-2952(01)00806-1

131. Stiborová M, Sejbal J, Bořek-Dohalská L, Aimová D, Poljaková J, Forsterová K, Rupertová M, Wiesner J, Hudeček J, Wiessler M, Frei E (2004) The anticancer drug ellipticine forms covalent DNA adducts, mediated by human cytochromes P450, through metabolism to 13-hydroxyellipticine and ellipticine N2-oxide. Cancer Res 64:8374-8380. https://doi.org/10.1158/0008-5472. CAN-04-2202

132. Aimová D, Stiborová M (2005) Antitumor drug ellipticine inhibits the activaties of rat hepatic cytochromes P450. Biomed Pap 149:437-440

133. Aimová D, Svobodová L, Kotrbová V, Mrázová B, Hodek P, Hudeček J, Václavíková R, Frei E, Stiborová M (2007) The anticancer drug ellipticine is a potent inducer of rat cytochromes P450 1A1 and 1A2, thereby modulating its own metabolism. Drug Metab Dispos 35:1926-1934. https://doi.org/10.1124/dmd. 107.016048

134. Wu Y, Sadatmousavi P, Wang R, Lu S, Yuan YF, Chen P (2012) Self-assembling peptide-based nanoparticles enhance anticancer effect of ellipticine in vitro and in vivo. Int J Nanomedicine 7:3221-3233. https://doi.org/10.2147/IJN.S31858

135. Chen Q, Liu J, Zhuang Y, ping Bai L, Yuan Q, Zheng S, Liao K, Khan MA, Wu Q, Luo C, Liu L, Wang H, Li T (2019) Identification of an IKK $\beta$ inhibitor for inhibition of inflammation in vivo and in vitro. Pharmacol Res 149:104440. https://doi.org/ 10.1016/j.phrs.2019.104440

136. Mikstacka R, Przybylska D, Rimando AM, Baer-Dubowska W (2007) Inhibition of human recombinant cytochromes P450 CYP1A1 and CYP1B1 by trans-resveratrol methyl ethers. Mol Nutr Food Res 51:517-524. https://doi.org/10.1002/mnfr.200600135

137. Albassam AA, Frye RF (2019) Effect of pterostilbene on in vitro drug metabolizing enzyme activity. Saudi Pharm J 27:406-412. https://doi.org/10.1016/j.jsps.2019.01.001

138. Eräsalo H, Hämäläinen M, Leppänen T, Mäki-Opas I, Laavola M, Haavikko R, Yli-Kauhaluoma J, Moilanen E (2018) Natural stilbenoids have anti-inflammatory properties in vivo and downregulate the production of inflammatory mediators NO, IL6, and MCP1 possibly in a PI3K/Akt-dependent manner. J Nat Prod 81:1131-1142. https://doi.org/10.1021/acs.jnatprod.7b00384

139. Nam W, Nam SH, Kim SP, Levin C, Friedman M (2019) Antiadipogenic and anti-obesity activities of purpurin in 3T3L1 preadipocyte cells and in mice fed a high-fat diet. BMC Complement Altern Med 19:364. https://doi.org/10.1186/ s12906-019-2756-5

140. Kim JK, Kim N, Lim YH (2010) Evaluation of the antibacterial activity of rhapontigenin produced from rhapontin by biotransformation against Propionibacterium acnes. J Microbiol Biotechnol 20:82-87. https://doi.org/10.4014/jmb.0907.07022

141. Chun YJ, Ryu SY, Jeong TC, Kim MY (2001) Mechanism-based inhibition of human cytochrome P450 1A1 by rhapontigenin. Drug Metab Dispos 29:389-393

142. Cieniak C, Liu R, Fottinger A, Smiley SAM, Guerrero-Analco JA, Bennett SAL, Haddad PS, Cuerrier A, Saleem A, Arnason JT, Foster BC (2013) In vitro inhibition of metabolism but not transport of gliclazide and repaglinide by Cree medicinal plant extracts. J Ethnopharmacol 150:1087-1095. https://doi.org/10. 1016/j.jep.2013.10.029

143. Roupe KA, Helms GL, Halls SC, Yáñez JA, Davies NMT (2005) Graduate program, preparative enzymatic synthesis and HPLC Analysis of rhapontigenin: applications to metabolism, 
pharmacokinetics and anti-cancer studies. J Pharm Pharm Sci 8:374-386. www.cspscanada.org (accessed July 9, 2020)

144. Roupe K, Remsberg C, Yanez J, Davies N (2006) Pharmacometrics of stilbenes: seguing towards the clinic. Curr Clin Pharmacol 1:81-101. https://doi.org/10.2174/157488406775268246

145. Fan Y (2019) Cardioprotective effect of rhapontigenin in isoproterenol-induced myocardial infarction in a rat model. Pharmacology 103:291-302. https://doi.org/10.1159/000496800

146. Asahina Y, Kashiwaki K (1915) chemical constituents of the fruits of Evodia rutaecarpa. J Pharm Soc Jpn 1293

147. Ueng Y-F, Jan W-C, Lin L-C, Chen T-L, Guengerich FP, Chen C-F (2002) The alkaloid rutaecarpine is a selective inhibitor of cytochrome P450 1A in mouse and human liver microsomes. Drug Metab Dispos 30:349-353. https://doi.org/10.1124/DMD.30.3.349

148. Ueng YF, Wang JJ, Lin LC, Park SS, Chen CF (2001) Induction of cytochrome $\mathrm{P} 450$-dependent monooxygenase in mouse liver and kidney by rutaecarpine, an alkaloid of the herbal drug Evodia rutaecarpa. Life Sci 70:207-217. https://doi.org/10.1016/S00243205(01)01390-X

149. Ueng Y-F, Tsai T-H, Don M-J, Chen R-M, Chen T-L (2005) Alteration of the pharmacokinetics of theophylline by rutaecarpine, an alkaloid of the medicinal herb Evodia rutaecarpa, in rats. J Pharm Pharmacol 57:227-232. https://doi.org/10.1211/0022357055489

150. Haarmann-Stemmann T, Sendker J, Götz C, Krug N, Bothe H, Fritsche E, Proksch P, Abel J (2010) Regulation of dioxin receptor function by different beta-carboline alkaloids. Arch Toxicol 84:619-629. https://doi.org/10.1007/s00204-010-0548-2

151. Han EH, Kim HG, Im JH, Jeong TC, Jeong HG (2009) Up-regulation of CYP1A1 by rutaecarpine is dependent on aryl hydrocarbon receptor and calcium. Toxicology 266:38-47. https://doi.org/10.1016/j.tox. 2009.10.013

152. Tian KM, Li JJ, Xu SW (2019) Rutaecarpine: a promising cardiovascular protective alkaloid from Evodia rutaecarpa (Wu Zhu Yu). Pharmacol Res 141:541-550. https://doi.org/10.1016/j.phrs. 2018.12.019

153. Hu CP, Li NS, Xiao L, Deng HW, Li YJ (2003) Involvement of capsaicin-sensitive sensory nerves in cardioprotection of rutaecarpine in rats. Regul Pept 114:45-49. https://doi.org/10.1016/ S0167-0115(03)00087-9

154. Li W-Q, Li X-H, Du J, Zhang W, Li D, Xiong X-M, Li Y-J (2016) Rutaecarpine attenuates hypoxia-induced right ventricular remodeling in rats, Naunyn. Schmiedebergs. Arch Pharmacol 389:757767. https://doi.org/10.1007/s00210-016-1240-8

155. Qin XP, Zeng SY, Li D, Chen QQ, Luo D, Zhang Z, Hu GY, Deng HW, Li YJ (2007) Calcitonin gene-related peptide-mediated depressor effect and inhibiting vascular hypertrophy of rutaecarpine in renovascular hypertensive rats. J Cardiovasc Pharmacol 50:654-659. https://doi.org/10.1097/FJC.0b013e3181579e7e

156. Li D, Peng J, Xin HY, Luo D, Zhang YS, Zhou Z, Jiang DJ, Deng HW, Li YJ (2008) Calcitonin gene-related peptide-mediated antihypertensive and anti-platelet effects by rutaecarpine in spontaneously hypertensive rats. Peptides 29:1781-1788. https://doi. org/10.1016/j.peptides.2008.06.010

157. Li D, Zhang XJ, Chen L, Yang Z, Deng HW, Peng J, Li YJ (2009) Calcitonin gene-related peptide mediates the cardioprotective effects of rutaecarpine against ischaemia-reperfusion injury in spontaneously hypertensive rats. Clin Exp Pharmacol Physiol 36:662-667. https://doi.org/10.1111/j.1440-1681.2008.05136.x

158. Zhou Z, Peng J, Wang CJ, Li D, Li TT, Hu CP, Chen XP, Li YJ (2010) Accelerated senescence of endothelial progenitor cells in hypertension is related to the reduction of calcitonin gene-related peptide. J Hypertens 28:931-939. https://doi.org/10.1097/HJH. 0b013e3283399326
159. Xu Y, Liu Q, Xu Y, Liu C, Wang X, He X, Zhu N, Liu J, Wu Y, Li Y, Li N, Feng T, Lai F, Zhang M, Hong B, Jiang JD, Si S (2014) Rutaecarpine suppresses atherosclerosis in ApoE-/- mice through upregulating ABCA1 and SR-BI within RCT. J Lipid Res 55:1634-1647. https://doi.org/10.1194/jlr.M044198

160. Xu Y, Chen XP, Zhang F, Hou HH, Zhang JY, Lin SX, Sun AS (2017) Rutaecarpine inhibits intimal hyperplasia in A ballooninjured rat artery model. Chin J Integr Med 24:429-435. https:// doi.org/10.1007/s11655-017-2900-3

161. Nie XQ, Chen HH, Zhang JY, Zhang YJ, Yang JW, Pan HJ, Song WX, Murad F, He YQ, Bian K (2016) Rutaecarpine ameliorates hyperlipidemia and hyperglycemia in fat-fed, streptozotocintreated rats via regulating the IRS-1/PI3K/Akt and AMPK/ACC2 signaling pathways. Acta Pharmacol Sin 37:483-496. https://doi. org/10.1038/aps.2015.167

162. Wang C, Hao Z, Zhou J, Zhang L, Sun Y, Liang C (2017) Rutaecarpine alleviates renal ischemia reperfusion injury in rats by suppressing the JNK/p38 MAPK signaling pathway and interfering with the oxidative stress response. Mol Med Rep 16:922928. https://doi.org/10.3892/mmr.2017.6631

163. Wang Z, Monti S, Sherr DH (2017) The diverse and important contributions of the AHR to cancer and cancer immunity. Curr Opin Toxicol 2:93-102. https://doi.org/10.1016/j.cotox.2017.01.008

164. Gutiérrez-Vázquez C, Quintana FJ (2018) Regulation of the immune response by the aryl hydrocarbon receptor. Immunity 48:19-33. https://doi.org/10.1016/j.immuni.2017.12.012

165. Xue P, Fu J, Zhou Y (2018) The aryl hydrocarbon receptor and tumor immunity. Front Immunol 9:13. https://doi.org/10.3389/ fimmu.2018.00286

166. A first-in-humans dose finding study for an aryl hydrocarbon receptor inhibitor (AhRi) in patients with advanced cancer (n.d.) https://clinicaltrials.gov/ct2/show/NCT04069026?term= aryl \&draw $=2 \&$ rank $=2$ (accessed 15 Dec 2020)

167. IK-175 in patients with advanced or metastatic solid tumors and urothelial carcinoma (n.d.) https://clinicaltrials.gov/ct2/show/ NCT04200963?term $=$ aryl\&draw $=2 \&$ rank $=4($ accessed 15 Dec 2020)

168. Loro E, Sengupta K, Bogdanovich S, Whig K, Schultz DC, Huryn DM, Khurana TS (2020) High-throughput identification of post-transcriptional utrophin up-regulators for Duchenne muscle dystrophy (DMD) therapy. Sci Rep 10:2143. https://doi.org/ 10.1038/s41598-020-58737-6

169. Wilkinson IVL, Perkins KJ, Dugdale H, Moir L, Vuorinen A, Chatzopoulou M, Squire SE, Monecke S, Lomow A, Geese M, Charles PD, Burch P, Tinsley JM, Wynne GM, Davies SG, Wilson FX, Rastinejad F, Mohammed S, Davies KE, Russell AJ (2020) Chemical proteomics and phenotypic profiling identifies the aryl hydrocarbon receptor as a molecular target of the utrophin modulator ezutromid. Angew Chemie Int Ed 59:2420-2428. https://doi. org/10.1002/anie.201912392

170. Muntoni F, Tejura B, Spinty S, Roper H, Hughes I, Layton G, Davies KE, Harriman S, Tinsley J (2019) A phase 1b trial to assess the pharmacokinetics of ezutromid in pediatric Duchenne muscular dystrophy patients on a balanced diet. Clin Pharmacol Drug Dev 8:922-933. https://doi.org/10.1002/cpdd.642

171. Proof of concept study to assess activity and safety of SMT C1100 (Ezutromid) in boys with Duchenne muscular dystrophy (DMD) (n.d.) https://clinicaltrials.gov/ct2/show/study/NCT02858362? term $=$ PhaseOut+DMD\&rank=1 (accessed 15 Dec 2020)

Publisher's Note Springer Nature remains neutral with regard to jurisdictional claims in published maps and institutional affiliations. 